\title{
Effects of Barometric Fluctuations on Well Water-Level Measurements and Aquifer Test Data
}

F. A. Spane, Jr.

December 1999

Prepared for

the U.S. Department of Energy

under Contract DE-AC06-76RLO 1830

Pacific Northwest National Laboratory

Richland, Washington 99352 



\section{DISCLAIMER}

This report was prepared as an account of work sponsored by an agency of the United States Government. Neither the United States Government nor any agency thereof, nor any of their employees, make any warranty, express or implied, or assumes any legal liability or responsibility for the accuracy, completeness, or usefulness of any information, apparatus, product, or process disclosed, or represents that its use would not infringe privately owned rights. Reference herein to any specific commercial product, process, or service by trade name, trademark, manufacturer, or otherwise does not necessarily constitute or imply its endorsement, recommendation, or favoring by the United States Government or any agency thereof. The views and opinions of authors expressed herein do not necessarily state or reflect those of the United States Government or any agency thereof. 


\section{DISCLAIMER}

Portions of this document may be illegible in electronic image products. Images are produced from the best available original document. 


\section{Summary}

The Pacific Northwest National Laboratory ${ }^{1}$, as part of the Hanford Groundwater Monitoring Project, examines the potential for offsite migration of contamination within underlying aquifer systems. Well water-level elevation measurements from selected wells within these aquifer systems commonly form the basis for delineating groundwater-flow patterns (i.e., flow direction and hydraulic gradient). In addition, the analysis of water-level responses obtained in wells during hydrologic tests provides estimates of hydraulic properties that are important for evaluating groundwater-flow velocity and transport characteristics.

Barometric pressure fluctuations, however, can have a discernible impact on well water-level measurements. These barometric effects may lead to erroneous indications of hydraulic head within the aquifer. Total hydraulic head (i.e., sum of the water-table elevation and the atmospheric pressure at the water-table surface) within the aquifer, not well water-level elevation, is the hydrologic parameter for determining groundwater-flow direction and hydraulic gradient conditions. Temporal variations in barometric pressure may also adversely affect well water-level responses obtained during hydrologic tests. If significant, adjustments or removal of these barometric effects from the test-response record may be required for quantitative hydraulic property determination.

This report examines the effects of barometric fluctuations on well water-level measurements and evaluates adjustment and removal methods for determining areal aquifer head conditions and aquifer test analysis. Two examples of Hanford Site unconfined aquifer tests are examined that demonstrate barometric response analysis and illustrate the predictive/removal capabilities of various methods for well water-level and aquifer total head values. Good predictive/removal characteristics were demonstrated with best corrective results provided by multiple-regression deconvolution methods.

\footnotetext{
${ }^{1}$ Pacific Northwest National Laboratory is operated by Battelle for the U.S. Department of Energy.
} 


\section{Acknowledgments}

A number of people outside Pacific Northwest National Laboratory contributed to the development of this report. In particular, T. Rasmussen (University of Georgia) provided test examples and discussions about the use of multiple-regression techniques for removing barometric effects from well water-level data. E. Weeks (U.S. Geological Survey) provided a modified version of the WBAR program that can be used to predict the transmission of atmospheric pressure changes through the vadose zone and its impact on closed- and open-well monitoring systems. Westbay Instruments, Inc. provided the use of a Westbay Modular Subsurface Data Acquisition System $\left(\right.$ MOSDAX $^{\mathrm{TM}}$ ) that was used to collect the field test data analyzed in this report.

Several Pacific Northwest National Laboratory staff provided significant contributions to this report's preparation. Technical peer review comments were provided by $P$. Thorne. Editorial review and graphics support given by B. Johnston and D. Newcomer are also acknowledged. Thanks are also extended to S. Wurstner for providing program software modifications. The financial support and patience extended by R. Smith and S. Luttrell for completion of project are also appreciated. 



\section{Contents}

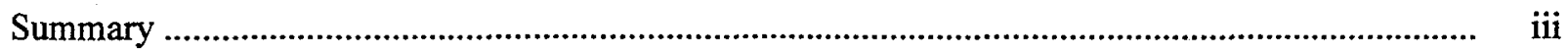

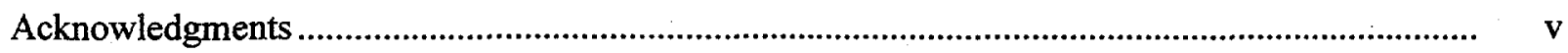

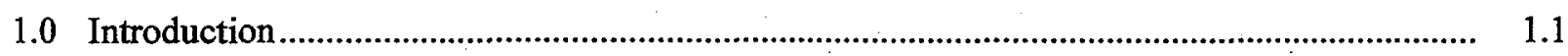

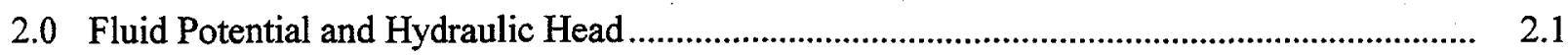

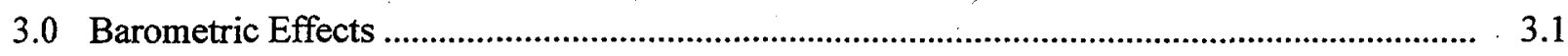

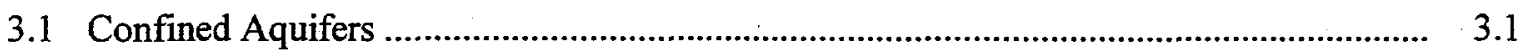

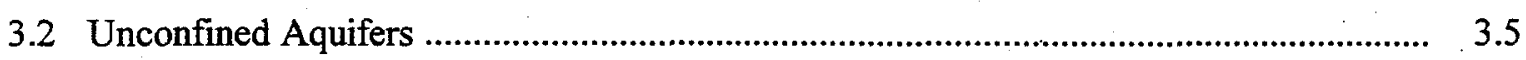

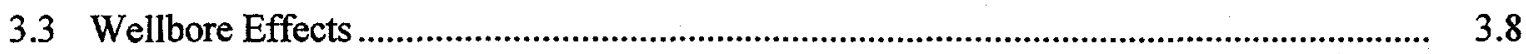

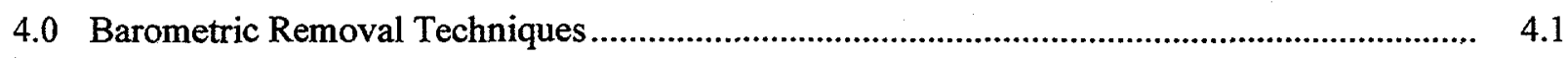

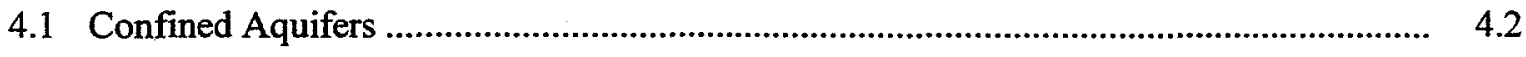

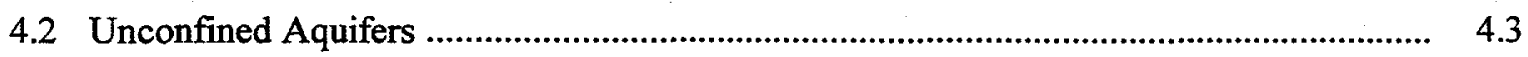

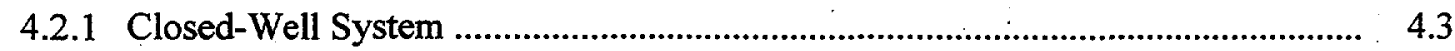

4.2.2 Multiple-Regression Techniques ....................................................................... 4.5

4.2.3 Vadose Zone Model............................................................................................. 4.13

4.2.4 Removal Method Comparison .................................................................... 4.17

5.0 Flow Direction and Hydraulic Gradient Determination...............................................

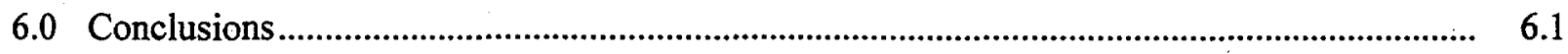

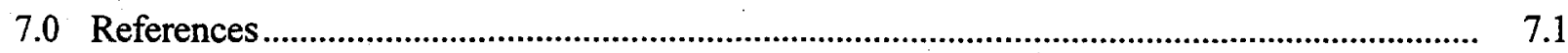




\section{Figures}

$3.1 \quad$ Well Barometric Pressure-Response Models ...................................................................... 3.2

3.2 Total Head Barometric Pressure-Response Models ..................................................... 3.2

3.3 Predicted Confined Aquifer/Well Water-Level Elevation and Hydraulic Head Response, Based on Hanford Meteorology Station 1998 Hourly Atmospheric Pressure Measurements

3.4 Unconfined Aquifer/Well Water-Level Elevation and Hydraulic Head Response for a 1-m Step Change in Atmospheric Pressure

3.5 Predicted Unconfined Aquifer/Well Water-Level Elevation and Hydraulic Head Response, Based on Hanford Meteorology Station 1998 Hourly Atmospheric Pressure Measurements

3.6 Diagnostic Barometric Response Function for Wellbore-Storage Model

3.7 Diagnostic Barometric Response Function for Wellbore-Storage and Positive Well-Skin Model

3.8 Composite Diagnostic Response Function for Wellbore-Storage/Confined Aquifer Model

3.9 Composite Diagnostic Response Function for Wellbore-Storage/Unconfined Aquifer Model

4.1 Total Head and Atmospheric Pressure Measurements for Well 699-43-42K Zone 3, August 6 - September 3, 1998

4.2 Total Head Barometric Response Patterns for Well 699-43-42K Zones 2, 3, and 4

4.3 Multiple-Regression Match and Barometric Correction of Closed-Well Total Head Response for Well 699-43-42K Zone 3

4.4 Total Head and Atmospheric Pressure Measurements for Well 699-43-42K Zone 3, September $7-30,1998$

4.5 Comparison of Open Versus Closed System Total Head Barometric Response Patterns for Zone 3 
4.6 Multiple-Regression Match and Barometric Correction of Open-Well Total Head Response for Well 699-43-42K Zone 3

4.7 Observed Well Water-Level, Calculated Total Head, and Atmospheric Pressure Measurements for Well 299-E33-41, January 30 - March 1, 1999

4.8 Comparison of Observed Well Water-Level and Calculated Total Head Barometric Response Patterns for Well 299-E33-41.

4.9 Multiple-Regression Match and Barometric Correction of Well Water-Level and Total Head Response for Well 299-E33-41

4.10 Vadose Zone Model Match of Well Water-Level Elevation and Total Head for Closed-Well 699-43-42K Zone 3

4.11 Vadose Zone Model Barometric Correction of Closed-Well Total Head Response for Well 699-43-42K Zone 3

4.12 Vadose Zone Model Match of Well Water-Level Elevation and Total Head for Open-Well 299-E33-41

4.13 Vadose Zone Model Barometric Correction of Open-Well Total Head Response for Well 299-E33-41

5.1 Location Map of Wells Monitoring the 216-B-63 Trench

5.2 Comparison of Well Water-Level Elevation Response for Selected Wells Monitoring the 216-B-63 Trench

5.3 Comparison of Well Water-Level Elevation and Atmospheric Pressure for Selected Wells Monitoring the 216-B-63 Trench, November 5-6, 1996

\section{Tables}

4.1 Multiple-Regression Analysis Results for Closed- and Open-Well System Measurements Obtained at Well 699-43-42K

5.1 Trend-Surface Hydraulic Gradient and Groundwater-Flow Direction Determinations for Selected Wells Monitoring the 216-B-63 Trench.

5.2 Trend-Surface Hydraulic Gradient and Groundwater-Flow Direction Determinations for Wells Monitoring the 216-B-63 Trench 


\subsection{Introduction}

As part of the Hanford Groundwater Monitoring Project, Pacific Northwest National Laboratory examines the potential on- and offsite migration of contamination within the shallow unconfined and underlying upper basalt-confined aquifer system. As part of this activity, water-level measurements (i.e., water-level elevations) are routinely monitored within selected wells completed in these aquifer systems to determine hydraulic head relationships. Analysis of hydraulic head conditions provides areal and temporal information that can be used in the development of a water-table, or potentiometric, map for inferring lateral groundwater-flow patterns (i.e., flow direction and hydraulic gradient) and for assessing the flow dynamics of the monitored aquifer system. In addition, analysis of hydraulic head responses, obtained in wells during hydrologic tests (e.g., pumping tests), provides estimates of hydraulic properties important for evaluating groundwater-flow velocity and transport travel time within the aquifer system.

Various factors can affect the accuracy of well water-level measurements and how they are used to determine hydraulic head and to infer groundwater-flow conditions within an aquifer. These factors include measurement error, well fluid-column density conditions, and external stress effects.

Measurement error includes the cumulative effect of instrument and measuring point elevation errors, borehole deviation, and random measurement factors, such as operator error. Relevant discussions pertaining to the assessment and correction of systematic components of measurement error are provided in Garber and Koopman (1968), Winograd (1970), Spane and Mercer (1985), and Spane and Thorne (1986). Well fluid-column density conditions relate to factors that affect the height of a fluid column in a well above a known elevation datum. Factors that can affect fluid-column density include fluid temperature, salinity, pressure, dissolved gas content, multiphase conditions, and gravitational acceleration effects. Generally, these factors are only significant for deep or thick aquifers having long fluid-column lengths. A program (HEADCO) that accounts for various fluid-column density factors is described in Spane and Mercer (1985). An application of the HEADCO program for converting/correcting well waterlevel measurements to total hydraulic head for the determination of groundwater-flow conditions within a confined aquifer system at the Hanford Site is presented in Spane (1987).

Natural external stresses that can influence well water-level measurements include barometric effects, tidal or river-stage fluctuations, and earth tides. Earlier papers have addressed these effects on well water-level measurements within confined and unconfined aquifer systems (e.g., Jacob 1940; Ferris 1963; Bredehoeft 1967; Weeks 1979; Hsieh et al. 1988; Erskine 1991). Only recently, however, has the importance of removing external stress factor effects from water-level measurements for wells monitoring shallow unconfined aquifer systems been recognized. This report focuses on applying barometric correction and removal techniques presented in Rasmussen and Crawford (1997) to confined and unconfined aquifer water-level measurements to determine groundwater-flow patterns and hydraulic property characterization. Specifically, this report

- defines the governing equations used to describe groundwater flow

- assesses the impact of barometric pressure fluctuations on water-level measurements in wells 
- evaluates the robustness of several methods for removal of barometric effects from hydrologic test data collected during aquifer tests

- recommends procedures for accounting for barometric effects in calculating aquifer hydraulic head values for determining groundwater-flow characteristics

- provides conclusions drawn from the calculations and discussions.

Information presented in this report pertains to conditions existing on the Hanford Site. The findings and recommended procedures, however, have universal application for aquifer systems, but will be particularly relevant for unconfined aquifer areas of small size and/or having low hydraulic gradient conditions, which make determining groundwater-flow direction and hydraulic gradients particularly difficult (e.g., 200 East Area of the Hanford Site). 


\subsection{Fluid Potential and Hydraulic Head}

Hubbert (1940) presented the derivation of the theory describing groundwater-flow conditions for homogeneous fluid systems (i.e., fluid properties invariant both spatially or with time) as being solely dependent on availability of energy per unit weight of the fluid. Hubbert (1940) described this dependence in terms of a scalar fluid or hydraulic potential, $\phi$

$$
\phi=g z_{i}+\left(P_{i}-P_{a}\right) / \rho+V^{2} / 2
$$

where $\mathrm{g}=$ acceleration due to gravity, $\mathrm{L} / \mathrm{T}^{2}$

$\mathrm{z}_{\mathrm{i}}=$ elevation of pressure measurement point, $\mathrm{P}_{\mathrm{i}}$, above a reference datum, $\mathrm{L}$

$P_{i}=$ absolute fluid-pressure measurement at point, $\mathrm{i}, \mathrm{F} / \mathrm{L}^{2}$

$P_{a}=$ atmospheric pressure at fluid surface, $F / L^{2}$

$\rho=$ fluid density, $M / L^{3}$

$\mathrm{V}=$ fluid velocity, $\mathrm{L} / \mathrm{T}$.

The first and second terms on the right-hand side of Equation (2.1) are the gravitational and pressure potential energy, respectively. If Darcian groundwater-flow conditions exist (i.e., low fluid-flow velocity), then the kinetic energy potential (the last term on the right) can be omitted, and Equation (2.1) can be reduced to

$$
\phi=\mathrm{gz}_{\mathrm{i}}+\left(\mathrm{P}_{\mathrm{i}}-\mathrm{P}_{\mathrm{a}}\right) / \rho
$$

As stated in Hubbert (1940) for Equation (2.2) to be strictly valid and unique, fluid density must be a function only of pressure. (Note: Nelson 1988 and Oberlander 1989 provide theoretical discussions for describing flow when groundwater is nonhomogeneous and/or fluid density is not solely dependent on pressure [e.g., temperature, salinity.])

Noting that the absolute fluid-pressure term can be expressed as a fluid-column height, $h$, above the measurement point, i, of a known or specified fluid density, Equation (2.2) can be expressed as

$$
\phi=g_{i}+\left[\left(\rho g h+P_{a}\right)-P_{a}\right] / p
$$

which Hubbert (1940) reduces to

$$
\phi=\mathrm{gh}
$$

Fluid potential, then, is equivalent to the product of the height of a fluid column of known density, above a reference datum, $\mathrm{z}$, and acceleration due to gravity. For groundwater investigations, the reference datum most commonly used is mean sea level, which is based on the National Geodetic Vertical Datum of 1929 (Heath 1983). In hydrologic investigations, the height of the fluid column, $\mathrm{h}_{\mathrm{fc}}$, above mean sea level is referred to as hydraulic head, H. For groundwater studies, hydraulic head within unconfined and 
confined aquifers is normally determined by obtaining water-level measurements from wells and converting these measurements to hydraulic head values. The "observed" hydraulic head, $\mathrm{H}_{0}$, obtained from water-level measurements can be expressed as

$$
\mathrm{H}_{\mathrm{o}}=\mathrm{W}_{\mathrm{e}}=\mathrm{E}-\mathrm{D}_{\mathrm{w}}
$$

where $\quad \mathrm{W}_{\mathrm{e}}=$ water-level elevation, above reference datum, $\mathrm{L}$

$\mathrm{E}$ = elevation of surface datum from which field measurement is made, $\mathrm{L}$

$D_{\mathrm{w}}=$ depth from surface datum to the fluid-column surface within the monitoring well, $\mathrm{L}$.

In a two-dimensional groundwater-flow system (e.g., an aquifer confined between adjacent lowpermeability units or an unconfined aquifer underlain by a low-permeability formation, with a nonfluctuating water table), point measurements of hydraulic head can be used to construct a potentiometric (hydraulic head) map that represents the areal distribution of hydraulic potential within the aquifer. Potentiometric maps can be used to infer directions of groundwater movement, with flow occurring normal to contours of equal potential or head in systems with isotropic hydraulic conductivity. In situations where fluid-column densities vary significantly within the study area, observed hydraulic heads must be corrected to a reference density fluid prior to use in potentiometric maps. The reference density fluid normally used in hydrologic investigations is water at standard temperature and pressure conditions, with a density equal to $\sim 1.00 \mathrm{~g} / \mathrm{cm}^{3}\left(0.999014 \mathrm{~g} / \mathrm{cm}^{3}\right.$; Spane and Mercer 1985). The observed hydraulic head value corrected to this reference density fluid is referred to as a freshwater head (Lusczynski 1961; De Wiest 1969).

The freshwater head, $\mathrm{H}_{\mathrm{fw}}$, can be expressed as a modification of the basic equation for observed hydraulic head (see Equation [2.5])

and

$$
\mathrm{H}_{\mathrm{fw}}=\left[\left(\mathrm{P}_{\mathrm{f}}-\mathrm{P}_{\mathrm{a}}\right) / \mathrm{p}_{\mathrm{fw}} \mathrm{g}\right]-\mathrm{z}_{\mathrm{i}}
$$

$$
\mathrm{H}_{\mathrm{o}}=\left[\left(\mathrm{P}_{\mathrm{f}}-\mathrm{P}_{\mathrm{a}}\right) / \mathrm{p}_{\mathrm{o}} \mathrm{g}\right]-\mathrm{z}_{\mathrm{i}}
$$

where

$$
\left(P_{f}-P_{a}\right)=\left[\left(p_{\circ} g\right) h_{f c}\right]-z_{i}
$$

and $\quad P_{f}=$ formation pressure (absolute) at measuring point, $i$, within the aquifer/well fluid column, $\mathrm{F} / \mathrm{L}^{2}$

$h_{\mathrm{fc}}=$ height of well fluid column above measuring point, $\mathrm{i}, \mathrm{L}$

$\mathrm{p}_{\mathrm{fw}}=$ density of freshwater at standard temperature and pressure $\left(0.999014 \mathrm{~g} / \mathrm{cm}^{3}\right), \mathrm{M} / \mathrm{L}^{3}$

$p_{0}=$ average density of well fluid column above measuring point, $i, M / L^{3}$.

Contouring areal freshwater heads produces a relief map of the potentiometric surface within a hydrogeologic unit from which lateral energy gradients and areas of high and low potential can be delineated (Toth 1978). Analysis of a freshwater potentiometric surface provides qualitative information about the lateral direction and rate of groundwater flow. 
The previous discussion on use of freshwater head (Equation [2.6]) or observed head (Equation [2.7]) for delineation of groundwater-flow patterns assumes that the atmospheric pressure is uniform over the area of investigation and/or the effects of atmospheric pressure variation (i.e., areal variation and what exists at the aquifer boundary) are insignificant in comparison to areal fluid-head variations (i.e., hydraulic gradient) within the aquifer. This requirement of uniformity and relative significance of atmospheric pressure is stated in theoretical discussions pertaining to groundwater flow as presented in Hubbert (1940), Jacob $(1940,1950)$, Toth $(1963,1978)$, and Freeze and Witherspoon $(1966,1967)$.

To define groundwater-flow conditions more exactly, the atmospheric pressure that exists at the upper aquifer boundary must be applied to the freshwater or observed hydraulic head described in Equations (2.6) and (2.7). The total head, $\mathrm{H}_{\mathrm{t}}$, can then be expressed either as

or

$$
\mathrm{H}_{\mathrm{t}}=\mathrm{H}_{\mathrm{fw}}+\mathrm{H}_{\mathrm{a}}
$$

$$
\mathrm{H}_{\mathrm{t}}=\mathrm{H}_{0}+\mathrm{H}_{\mathrm{a}}
$$

where $\mathrm{H}_{\mathrm{a}}$ is the atmospheric head component, $\mathrm{L}$.

These total head expressions are consistent with total head relationships presented in Hubbert (1940), Domenico (1972), and Rasmussen and Crawford (1997). Depending on whether freshwater or observed head is used to delineate groundwater flow within a region (i.e., Equations [2.6] or [2.7]), the atmospheric head component of the total head is equal either to $\mathrm{P}_{\mathrm{a}} /\left(\mathrm{p}_{\mathrm{fw}} \mathrm{g}\right)$ or $\mathrm{P}_{\mathrm{a}} /\left(\mathrm{p}_{\mathrm{o}} \mathrm{g}\right)$. Commonly, the atmospheric head component is calculated as an incremental value referenced to an arbitrary atmospheric pressure standard, $\mathrm{P}_{\text {std. }}$. For example at the Hanford Site, Spane (1987) used the long-term average 10.087-m atmospheric pressure value recorded at the Hanford Meteorology Station, while Rasmussen and Crawford (1997) used the standard 10.333-m atmospheric pressure at mean sea level for their study at Savannah River.

While potentiometric maps are commonly used to depict steady- or pseudosteady-state conditions within an aquifer, transient external stress effects (e.g., barometric pressure, river-stage fluctuations) can exert a pronounced effect on field measurements within wells that are used to develop areal, steady-state head relationships within aquifer systems. These transient effects on measurements made within wells should be known and removed or accounted for. The removal of external stresses requires the systematic correlation of baseline head-monitoring measurements with observed external stress fluctuations. As will be discussed, the removal of external stress effects is different for confined and unconfined aquifer systems.

Once the relationship between the external stress and well hydraulic head measurements is established, the variation of the external stress from a standard reference value can be effectively removed from the hydraulic head measurement. An example of the effective removal of external stresses (i.e., barometric and Columbia River stage fluctuations) from water-level measurements obtained at a Hanford Site confined aquifer-monitoring well is presented in Spane (1993). A detailed description of methods for removing barometric pressure effects is presented in Section 4.0. 


\subsection{Barometric Effects}

Well water-level elevations and hydraulic head conditions within aquifers commonly respond to variations in atmospheric pressure. Barometric fluctuations represent an areal, blanket stress applied directly at land surface and to the open well water-level surface. The manner in which a well/aquifer system responds to changes in atmospheric pressure, however, is variable and directly related to the degree of aquifer confinement and hydraulic/storage characteristics of the well/aquifer system. Rasmussen and Crawford (1997) identified three conceptual models that describe well water-level measurement response associated with barometric pressure change. These include an instantaneous well response within confined aquifers, a delayed well response within unconfined aquifers (because of the delayed transmission of barometric pressure through the vadose zone), and a delayed well response associated with well characteristics (i.e., wellbore-storage and well-skin effects).

Rasmussen and Crawford (1997) provided a method for distinguishing the operative response model affecting well water-level measurements associated with barometric pressure change. Diagnostic plots for the three well-response models are shown in Figure 3.1. The plots show the time-lag dependence of each barometric response model associated with a unit step change in atmospheric pressure. As shown in Figure 3.1, each barometric response model has a distinguishing shape pattern that can be used diagnostically for response-model identification. As might be expected, composite responses can occur between the wellbore-storage model and either aquifer model. It should be noted that the barometric model patterns indicated in Figure 3.1 are specifically for well water-level response. Different barometric response relationships would occur for total head conditions within the aquifer (i.e., non-well-response models). Figure 3.2 shows the total head barometric response models within confined and unconfined aquifer systems; wellbore effects are not represented as an aquifer model response. As shown, the instantaneous and delayed aquifer-response patterns for confined and unconfined aquifer systems are the inverse to those exhibited for the well water-level-response patterns presented in Figure 3.1. For confined aquifers, the total head-response pattern is a function of $1-\mathrm{BE}$, which contrasts with the well response that is a function of barometric efficiency, BE. For unconfined aquifers, the total head response displays a buildup (increasing) pattern, which contrasts inversely with the decreasing well-response pattern shown in Figure 3.1 (unconfined aquifer model). A discussion of the relationship between barometric efficiency and each individual barometric response model is presented below.

\subsection{Confined Aquifers}

For confined aquifers, the transmission of atmospheric pressure effects is instantaneous (i.e., both to the well and aquifer), with the magnitude of water level and formation pressure change (at any particular locality) being functions of the degree of aquifer confinement, rigidity of the aquifer matrix, and specific weight of groundwater. Jacob (1940) was first to define the associated barometric response change in water level within an open well that monitors a confined aquifer as the well/aquifer system barometric efficiency:

$$
\mathrm{BE}=-\gamma_{\mathrm{fc}}\left(\Delta \mathrm{h}_{\mathrm{w}} / \Delta \mathrm{P}_{\mathrm{a}}\right)
$$




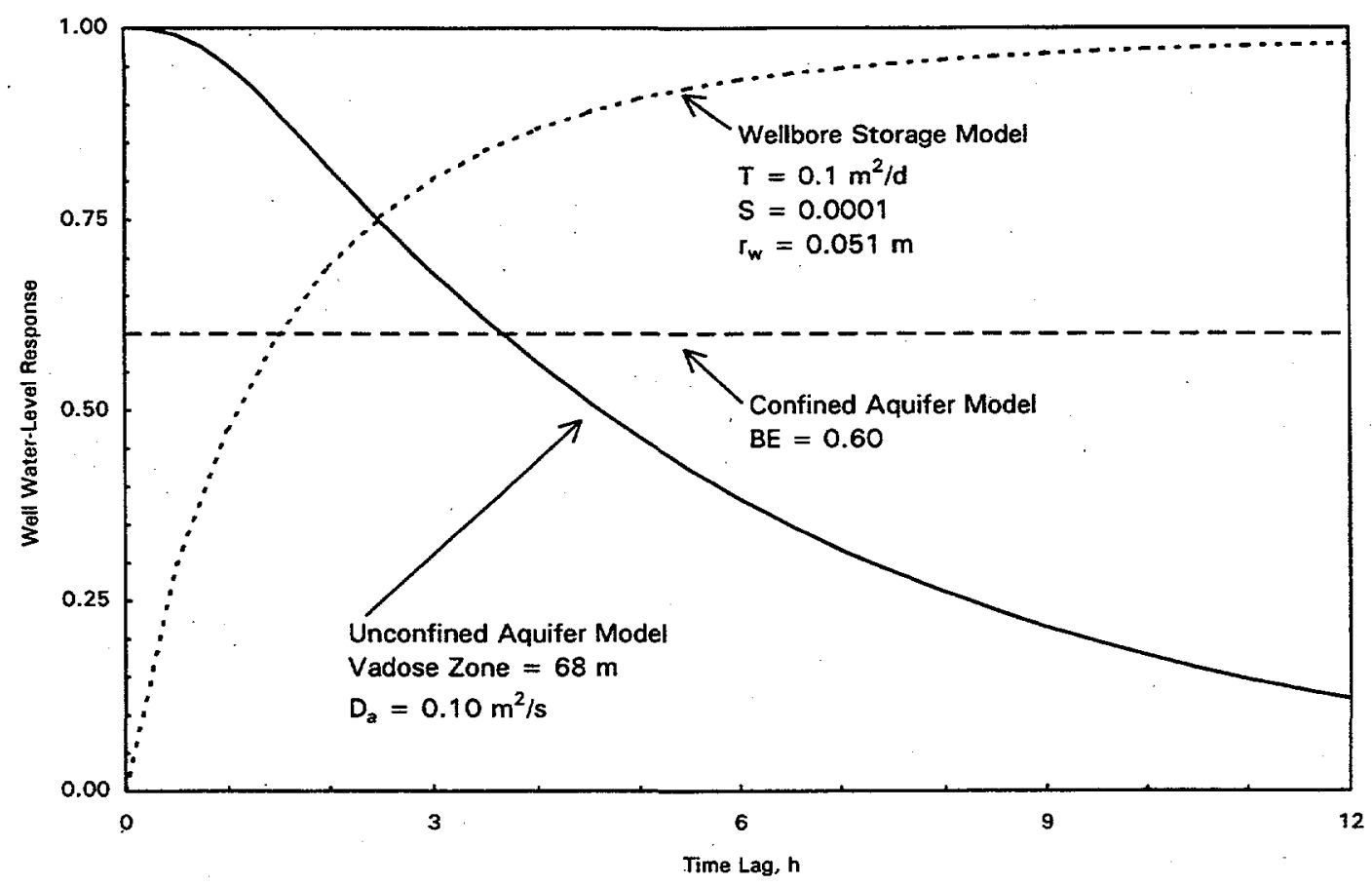

Figure 3.1. Well Barometric Pressure-Response Models

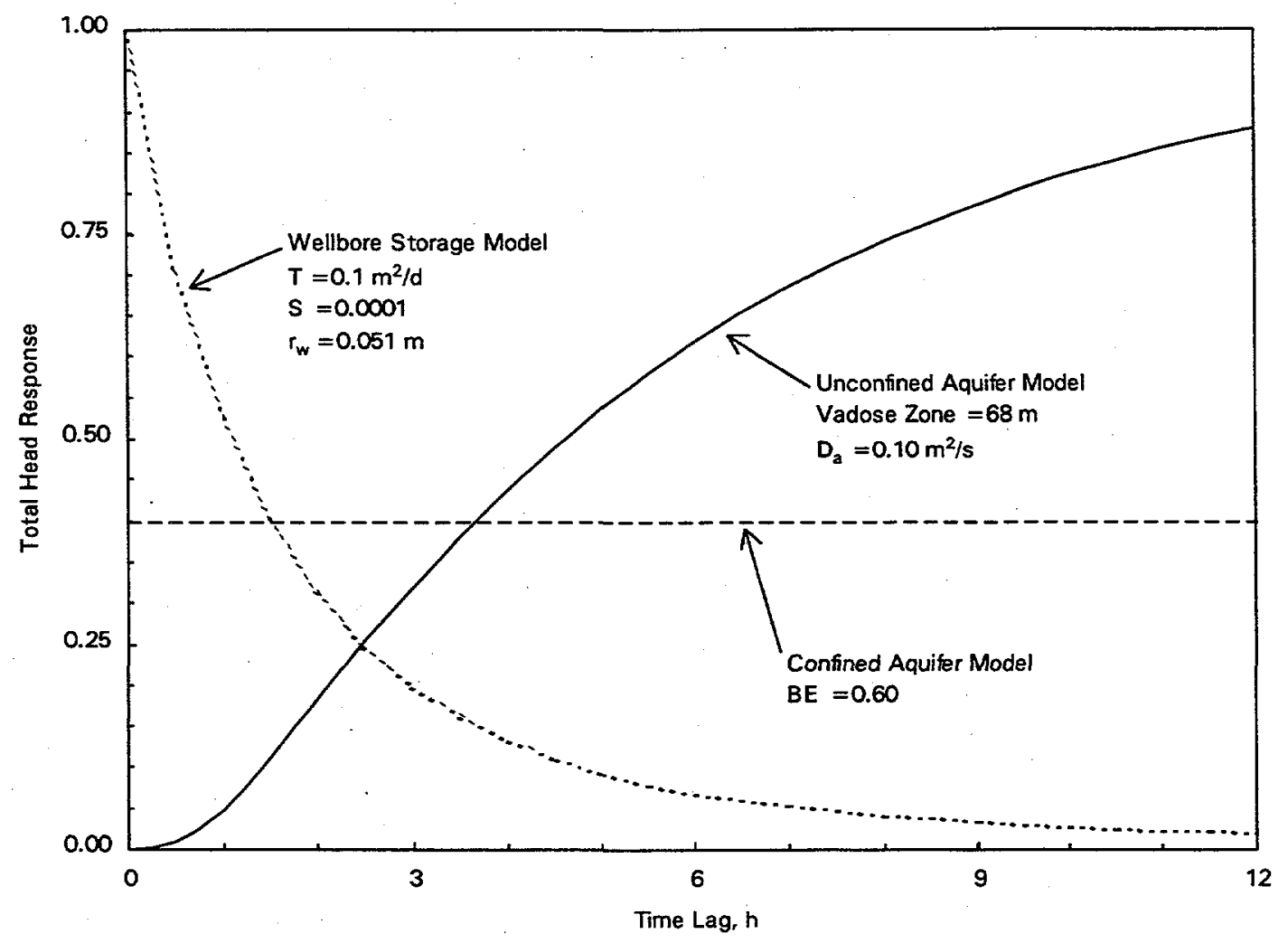

Figure 3.2. Total Head Barometric Pressure-Response Models 
where $\quad \gamma_{\mathrm{fc}}=$ average specific weight of the fluid column in the well, $\mathrm{F} / \mathrm{L}^{3}$

$\Delta \mathrm{h}_{\mathrm{w}}=$ change in elevation of the well fluid column associated with atmospheric pressure change, $\mathrm{L}$

$\Delta \mathrm{P}_{\mathrm{a}}=$ change in atmospheric pressure, $\mathrm{F} / \mathrm{L}^{2}$.

It should be noted that the minus sign in Equation (3.1) is reflective of the inverse relationship between fluid-column elevation and atmospheric pressure change (e.g., fluid-column elevation declines with an increase in atmospheric pressure).

Downhole pressure measured within an open well is in equilibrium with the pressure in the confined aquifer, $P_{f}$, at the measurement elevation point. The aquifer pressure responds immediately to atmospheric pressure fluctuations but at a magnitude equal to the atmospheric pressure change minus the pressure change caused by the change in the fluid-column elevation within the well (Spane and Mercer 1985):

$$
\Delta \mathrm{P}_{\mathrm{f}}=\Delta \mathrm{P}_{\mathrm{a}}+\gamma_{\mathrm{fc}} \Delta \mathrm{h}_{\mathrm{w}}
$$

or combining with Equation (3.1):

$$
\Delta \mathrm{P}_{\mathrm{f}}=(1-\mathrm{BE}) \Delta \mathrm{P}_{\mathrm{a}}
$$

Equations (3.2) and (3.3) indicate that the change in downhole formation pressure represents only that portion of the atmospheric pressure change not borne by the test formation matrix. Therefore, high barometric efficiencies reflect high strength and rigid test formations, while low barometric efficiencies indicate highly compressible formations. In the extreme case of $\mathrm{BE}=1, \mathrm{P}_{\mathrm{f}}$ does not vary with barometric changes and $\Delta \mathrm{P}_{\mathrm{a}}$ is offset by an equivalent change in well water level.

The method described in Clark (1967) is particularly useful for calculating barometric efficiencies from confined aquifer wells that are influenced by other extraneous pressure trends (e.g., distant groundwater withdrawals). Briefly stated, the method determines the barometric efficiency from the slope of a summation plot of the incremental changes in downhole formation pressure, $\Sigma \Delta \mathrm{P}_{\mathrm{f}}$, versus the incremental change in atmospheric pressure, $\Sigma \Delta \mathrm{P}_{\mathrm{a}}$. Incremental changes in downhole formation pressure are added to the summation total when the incremental sign change is equal to that of the incremental atmospheric pressure, $\Delta \mathrm{P}_{\mathrm{a}}$, sign change for the observed incremental period (e.g., when $\Delta \mathrm{P}_{\mathrm{f}}$ and $\Delta \mathrm{P}_{\mathrm{a}}$ are both positive or negative). Conversely, incremental changes in downhole formation pressure are subtracted from the summation total when the incremental sign change is unequal to that of the incremental atmospheric pressure sign change for the observed period. In addition, no incremental change in downhole formation pressure is added to the summation total when no change in atmospheric pressure is recorded. A slightly modified form of the Clark method was employed with good results by Davis and Rasmussen (1993) in determining barometric efficiencies of confined aquifers at the Hanford Site.

To examine the possible magnitude of barometric effects on formation pressure and well water-level measurements for confined aquifers on the Hanford Site, hourly atmospheric pressure readings measured at the Hanford Meteorology Station were examined for the year 1998. Atmospheric pressure changes are 
expressed in this report as equivalent change in freshwater head (in meters). During 1998, a maximum range in atmospheric pressures of $0.508 \mathrm{~m}$ was recorded (9.838 to $10.346 \mathrm{~m}$ of water), with the greatest variability occurring from fall through late spring because of the occurrence of frequent Pacific storms. In contrast, less variability is exhibited during the summer months and is primarily associated with diurnal heating and cooling.

The mean 1998 hourly value of $10.061 \mathrm{~m}$ is only slightly less than the reported long-term hourly average value of $10.087 \mathrm{~m}$ reported by Hoitink et al. (1999). The greatest daily atmospheric pressure change ever observed for the Hanford Site is reported to be $0.35 \mathrm{~m}$ (Hoitink et al. 1999).

Figure 3.3 shows a comparison of observed July through December 1998 hourly atmospheric pressures and predicted total hydraulic head and well water-level elevations. The predicted values were calculated using Equations (2.10) and (3.3), a BE value of 0.7, and an initial total head/water-level elevation of $150 \mathrm{~m}$ above mean sea level. It is important to note that the water-level elevations predicted for the well example are not equal to the total head conditions within the adjoining aquifer. This is because the change in applied atmospheric pressure is not accounted for by the surface-based depth-towater measurements (Equation [2.5]). Total head, however, can be calculated directly from downhole absolute pressure values (Equation [2.7]). This is because the well water-level elevation varies by $-\mathrm{BE}$ to a step change in atmospheric pressure (Equation [3.1]), while downhole formation pressure changes by $+(1-\mathrm{BE}$ ) (Equation [3.3]). Based on the example shown in Figure 3.3, a maximum well water-level fluctuation of $0.356 \mathrm{~m}$ and a maximum $0.152-\mathrm{m}$ change in total head would be predicted using the observed 1998 atmospheric pressure record.

Figure 3.3 clearly shows the inverse relational difference between water-level elevation, $\mathrm{W}_{e}$, and observed hydraulic head, $H_{0}$. W $W_{e}$ varies by $-B E\left(\Delta P_{a}\right)$, while $H_{o}$ fluctuates by $(1-B E)\left(\Delta P_{a}\right)$. The $0.7 B E$ value used in the example is indicative of a rigid confined aquifer system, as would be expected for the underlying basalt-confined aquifer system at the Hanford Site. For sediment-confined aquifers, significantly lower $\mathrm{BE}$ values would be expected. For $\mathrm{BE}$ values $<0.5$, associated barometric responses in aquifer hydraulic head would be greater than water-level elevation fluctuations.

It is also important to note again that the downhole absolute pressure, $P_{f}$, within the well fluid column and aquifer (for a given depth elevation) are equal. This is because the effects of atmospheric pressure stress are applied uniformly and instantaneously, both at the fluid-column surface in the well, as well as causing a change in downhole formation pressure equal to that shown in Equations (3.2) and (3.3). If an absolute pressure gauge is not used to obtain monitoring well measurements, total head within the aquifer can be calculated by simply adding the incremental change in atmospheric pressure from the reference value to the observed head determined from a well water-level measurement (Equation [2.5]), as indicated in Equation [2.10]).

As noted by Rasmussen and Crawford (1997), the diagnostic barometric response pattern for a confined aquifer model is distinguished by a constant well-response function for a step in pressure for all time lags (see Figure 3.1). This constancy in barometric response is attributed to the lack of dependence on lagged barometric response (i.e., barometric effects are applied "instantaneously" both at the well 


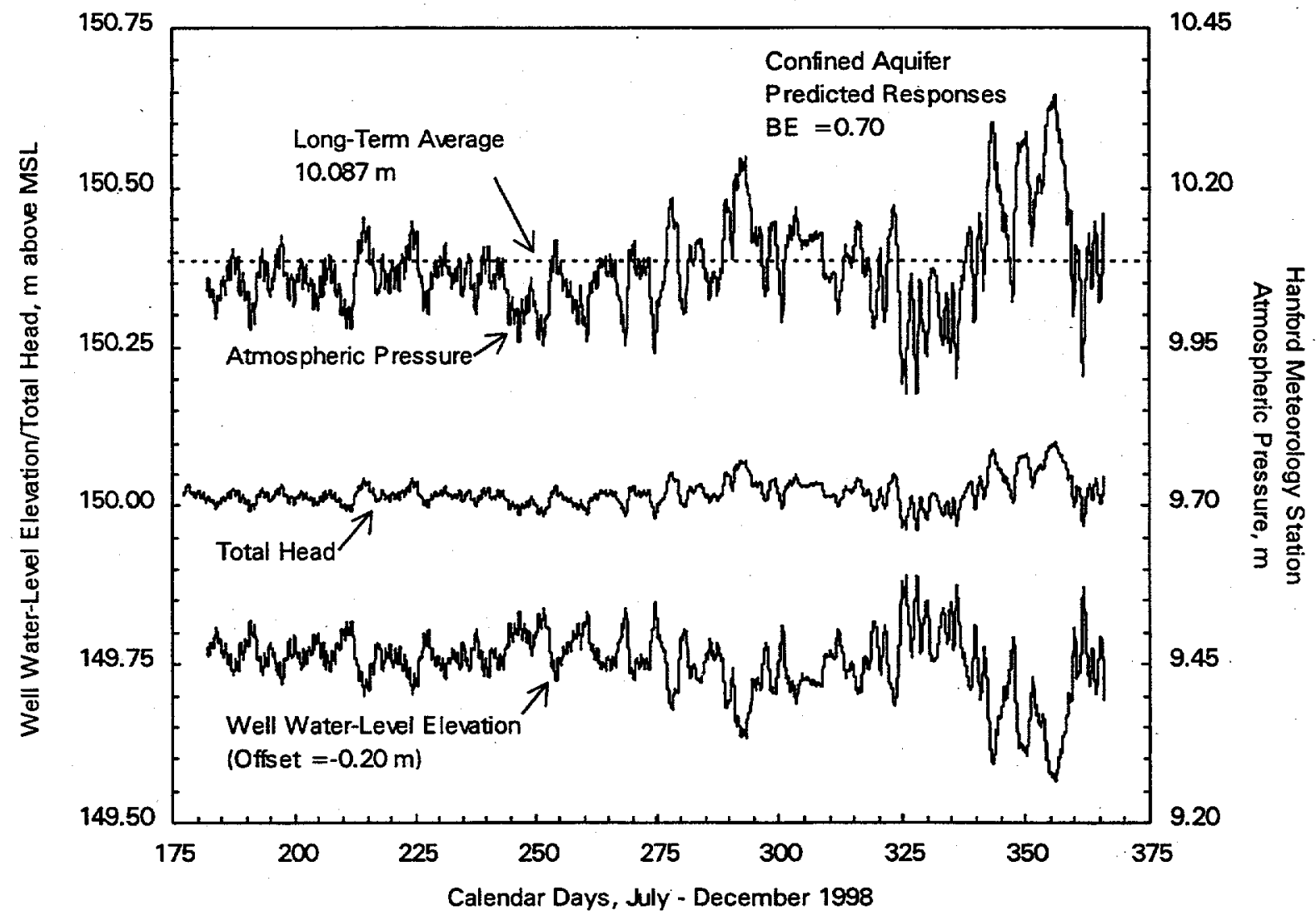

Figure 3.3. Predicted Confined Aquifer/Well Water-Level Elevation and Hydraulic Head Response, Based on Hanford Meteorology Station 1998 Hourly Atmospheric Pressure Measurements

and to the aquifer system). For the example shown, a $0.6 \mathrm{BE}$ value is indicated. For this condition, the total hydraulic head within the confined aquifer would change instantaneously by $4 / 10^{\text {ths }}$ the barometric change amount. In contrast, the well water-level elevation would change inversely by $6 / 10^{\text {ths }}$ the barometric change amount.

\subsection{Unconfined Aquifers}

Although wells monitoring unconfined aquifers respond to barometric pressure fluctuations, different mechanisms are involved than previously described for confined aquifer systems. As noted by Rasmussen and Crawford (1997), the diagnostic barometric response pattern for an unconfined aquifer well completed below the water table is distinguished by a decreasing water-level response pattern for a step change in pressure for increasing time lags (see Figure 3.1 [unconfined aquifer model]). This characteristic response pattern is caused by an imbalance in atmospheric pressure values within the well/aquifer system. For an open unconfined aquifer system, atmospheric pressure changes are transmitted instantaneously at the well, but display a time-lagged response at the water table because air must move into or out of the overlying vadose zone to transmit the change in pressure. The rate of air movement within the vadose zone is a direct function of its vertical pneumatic diffusivity (Weeks 1979) that, in turn, is a 
function of the vadose zone vertical permeability, moisture content, and compressibility of contained gas. For vadose zones exhibiting low pneumatic diffusivities and/or significant thickness, unconfined aquifer wells will exhibit major water-level fluctuations (i.e., apparently high barometric efficiency values) because of atmospheric fluctuations. This type of behavior, when viewed versus time (e.g., well waterlevel hydrograph), appears to be very similar to confined aquifer behavior. However, when analyzed diagnostically (as shown in Figure 3.1) versus lagged time, the unconfined aquifer exhibits a distinctly. different response pattern.

To illustrate the well/aquifer dynamics associated with atmospheric pressure fluctuations propagated through the vadose zone to the water table and its associated response on open well water levels, the Weeks (1979) vadose zone air-flow model, WBAR, was used. Figure 3.4 shows the predicted water-level elevation response and aquifer total head response resulting from a single step change in atmospheric pressure of $+1 \mathrm{~m}$ for three indicated vadose zone pneumatic diffusivities, $\mathrm{D}_{\mathrm{a}}$, and for a vadose zone thickness of $75 \mathrm{~m}$. As indicated for the low $D_{a}$ value case $\left(0.002 \mathrm{~m}^{2} / \mathrm{s}\right)$, the propagation of the atmospheric pressure change is delayed several days and reaches only $25 \%$ of the total step change 6 days after initiation of the step increase. As a consequence, water levels within the well would be "rapidly" depressed by the full amount of the atmospheric pressure change (i.e., $1 \mathrm{~m}$ ) because of the direct application of the pressure step to the open well fluid-column surface. The well water-level elevation would then recover to the pre-step static level on arrival of the atmospheric pressure signal through the vadose zone to the water-table surface. As also shown in Figure 3.4, more rapid well water-level recovery is

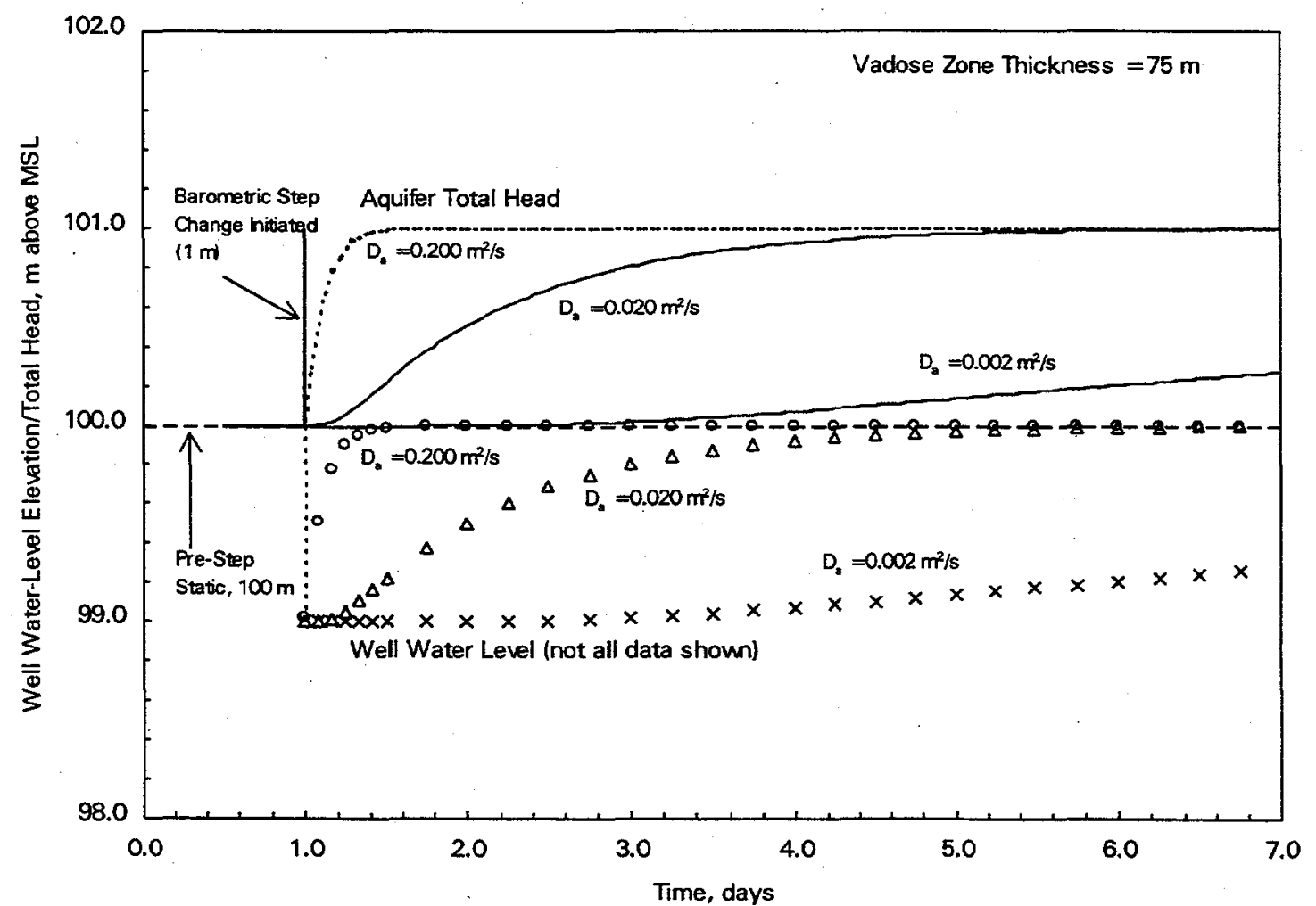

Figure 3.4. Unconfined Aquifer/Well Water-Level Elevation and Hydraulic Head Response for a 1-m Step Change in Atmospheric Pressure 
exhibited for increasing vadose zone $\mathrm{D}_{\mathrm{a}}$ values. It is important to note that the water-level recovery profiles parallel the total head profile buildup and can be duplicated by simply adding the atmospheric pressure change component (i.e., $1 \mathrm{~m}$ ) to the observed water-level elevation response, as was discussed for the confined aquifer case.

To assess the magnitude of barometric fluctuation effects on predicted well water-level elevations and total heads for unconfined aquifers on the Hanford Site, hourly atmospheric pressure readings measured at the Hanford Meteorology Station were examined for 1998. Figure 3.5 shows a comparison of observed July through December 1998 hourly atmospheric pressures and predicted total head and well water-level elevations. The predictions are based on the WBAR program (Weeks 1979) and an initial total head/ water-level elevation of $150 \mathrm{~m}$ above mean sea level. As in the confined aquifer evaluation, it is important to note that the predicted water-level elevations for the unconfined aquifer/well example are not equal to the total head conditions within the adjoining aquifer (if determined by surface-based depth-towater measurements-Equation [2.5]). The total head in the aquifer is, instead, equivalent to the downhole absolute pressure values (Equation [2.7]) because the well water-level elevation varies inversely by the change in atmospheric pressure (as applied at the well) minus the change in atmospheric pressure reaching the water table. The total head within the unconfined aquifer varies directly by the amount of

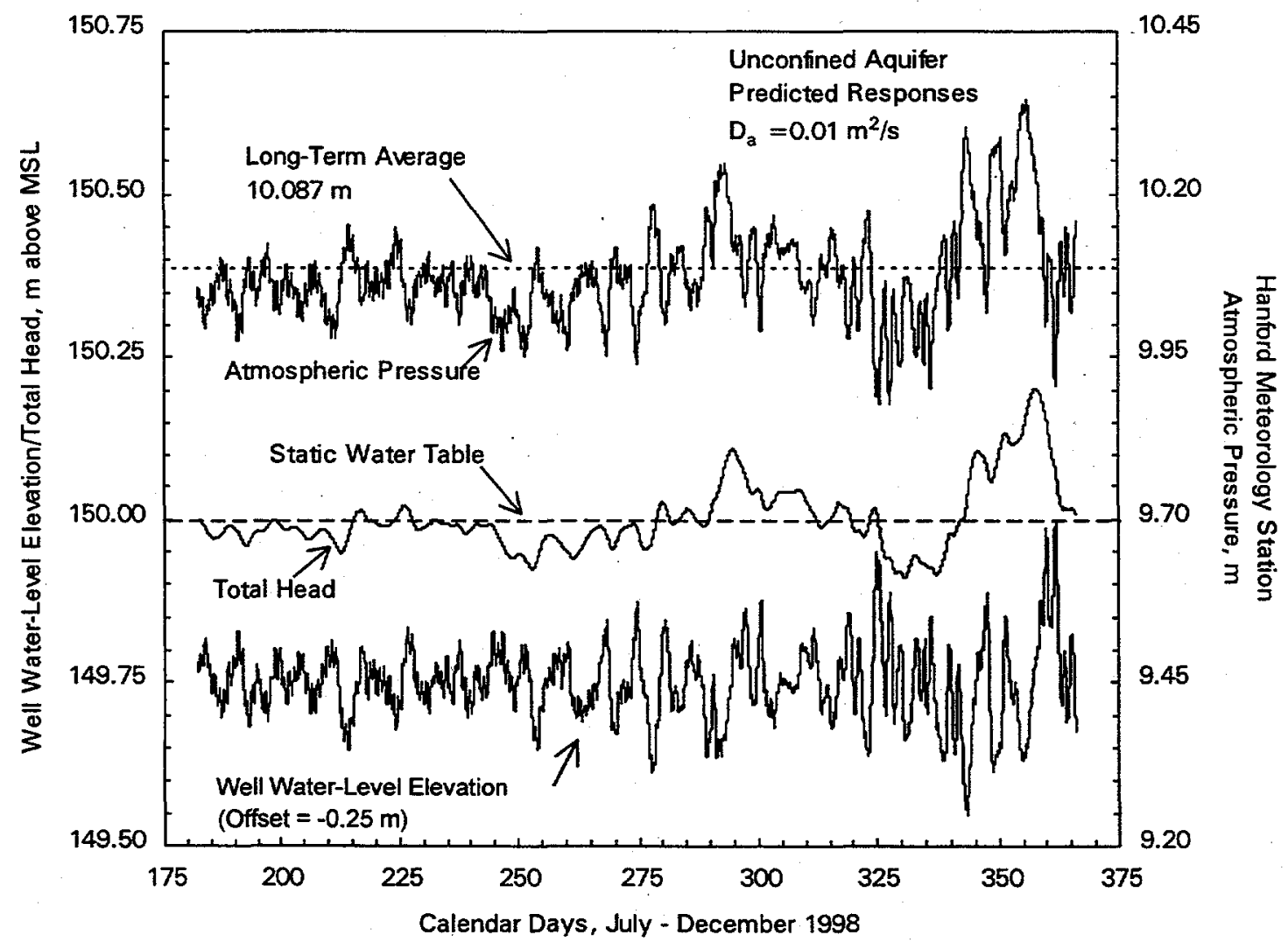

Figure 3.5. Predicted Unconfined Aquifer/Well Water-Level Elevation and Hydraulic Head Response, Based on Hanford Meteorology Station 1998 Hourly Atmospheric Pressure Measurements (pneumatic diffusivity, $D_{a}=0.01 \mathrm{~m}^{2} / \mathrm{s}$ ) 
atmospheric pressure change reaching the water table, which as discussed previously is a time-delayed process. Based on the example shown in Figure 3.5, a maximum well water-level fluctuation of $0.454 \mathrm{~m}$ and a maximum $0.292-\mathrm{m}$ change in total head would be predicted using the observed 1998 atmospheric pressure record.

\subsection{Wellbore Effects}

The discussions pertaining to barometric pressure effects within confined and unconfined aquifer systems assume that no delay occurs in transmitting changes in barometric pressure from the well to the aquifer system. In reality, the transmission of the barometric pressure change between the well/aquifer system is delayed because of the time required for movement of a finite volume of water between the well and the surrounding aquifer. The time delay associated with the movement of wellbore fluid is dependent on the aquifer properties (i.e., transmissivity, storativity) and existing well/borehole conditions (i.e., wellbore-storage and well-skin effects).

Because of the pressure imbalance characteristics that exist between a well and aquifer at the instant of barometric change, previous investigators (e.g., Furbish 1991) have noted that these momentary pressure imbalances can be treated as individual step changes in pressure (i.e., $\Delta \mathrm{P}_{\mathrm{a}}[1-\mathrm{BE}]$ ), which are applied at the well. These applied barometric pressure steps can be treated as individual well slug tests, which can be superimposed to provide the combined pressure response transmitted to the aquifer. Furbish (1991) and Rasmussen and Crawford (1997) used the Hvorslev (1951) slug test model for describing this barometric well response, based primarily on aquifer properties. However, because of the limiting assumptions of the Hvorslev model pertaining to wellbore storage as noted in Butler (1998), the analytically based Cooper et al. (1967) method can be used more rigorously to describe delayed barometric induced responses caused by wellbore-storage and/or similar models that account for both wellborestorage and well-skin effects (Novakowki 1990; Liu and Butler 1995).

Figure 3.6 shows the diagnostic well-response function for a slug test affected by wellbore storage for a unit step change in barometric pressure. The predicted slug test/wellbore response was calculated using the Kansas Geological Survey slug test model described in Butler (1998) and the following aquifer/well properties: transmissivity $0.01,0.1,1.0 \mathrm{~m}^{2} / \mathrm{d}$; storativity 0.0001 ; well casing radius $0.051 \mathrm{~m}$. As indicated in Figures 3.1 and 3.6, the wellbore-response function is distinctly different than the instantaneous/ constant pattern exhibited by a confined aquifer and opposite that exhibited by an unconfined aquifer model. The delayed wellbore response is a function solely of the aquifer and well properties. As shown in Figure 3.6, lower aquifer transmissivity values significantly increase the delayed nature (time lag) of the well-response function. For most common well/aquifer conditions, no observable time lag would be expected for transmissivity values greater than $\sim 10 \mathrm{~m}^{2} / \mathrm{d}$ (i.e., $>95 \%$ of the wellbore effect is dissipated within $5 \mathrm{~min}$ ). Increasing wellbore radius and decreasing aquifer storativity also cause increases in timelag behavior.

It should also be noted that the wellbore-storage responses shown are for the case of no skin/damage effects (i.e., skin =0). Positive well-skin effects cause an extension in the time delay associated with wellbore storage. Figure 3.7 illustrates this additional delay for the wellbore-storage-response patterns shown in Figure 3.6. A positive skin factor of +6.2 was used in developing the combined 


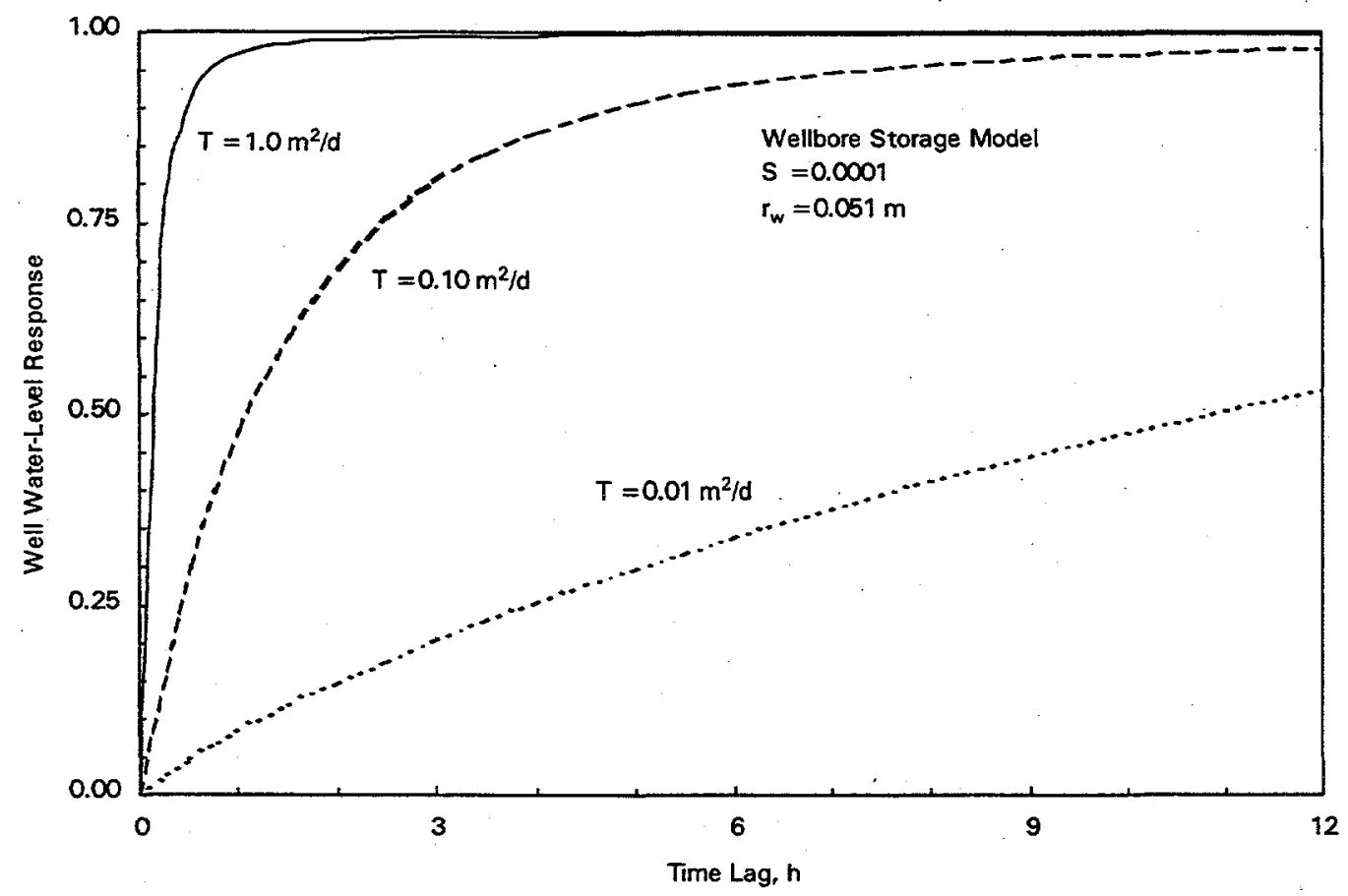

Figure 3.6. Diagnostic Barometric Response Function for Wellbore-Storage Model

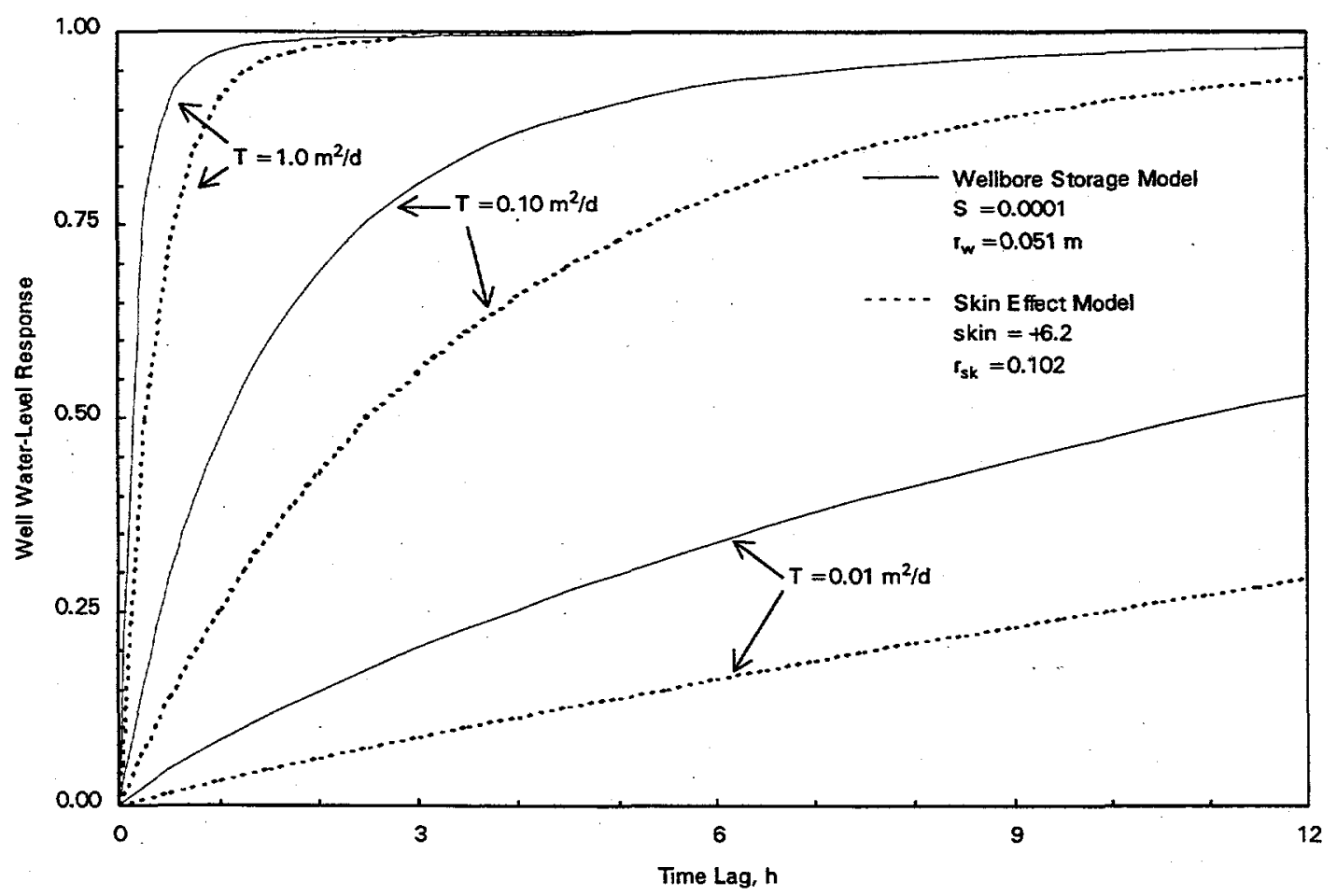

Figure 3.7. Diagnostic Barometric Response Function for Wellbore-Storage and Positive Well-Skin Model 
wellbore-storage/skin-response patterns shown. For illustrative purposes, a positive skin of +6.2 , based on the standard finite-thickness skin relationship presented in Earlougher (1977), is equivalent to a damaged zone having a reduced hydraulic conductivity equal to $1 / 10^{\text {th }}$ the aquifer, extending an additional wellbore radius from the well $\left(r_{\mathrm{skin}}=0.102 \mathrm{~m}, \mathrm{r}_{\mathrm{w}}=0.051 \mathrm{~m}\right)$ into the surrounding aquifer.

It should be noted that, in reality, a well-response pattern, based only on wellbore-storage/slug-test behavior, would not occur without also being associated with either a confined or unconfined aquifer well response. For such composite models, the initial and early time-lag responses follow the wellbore-storage pattern, transitioning in later time to the appropriate aquifer model. To illustrate a composite wellresponse pattern, the combined wellbore-storage and confined and unconfined aquifer models are shown in Figures 3.8 and 3.9, respectively. The same wellbore-storage conditions in Figure 3.6 were used in Figures 3.8 and 3.9 together with the indicated aquifer and well properties. Rasmussen and Crawford (1997) provided similar field test example plots, displaying a composite wellbore-storage and aquifer model behavior.

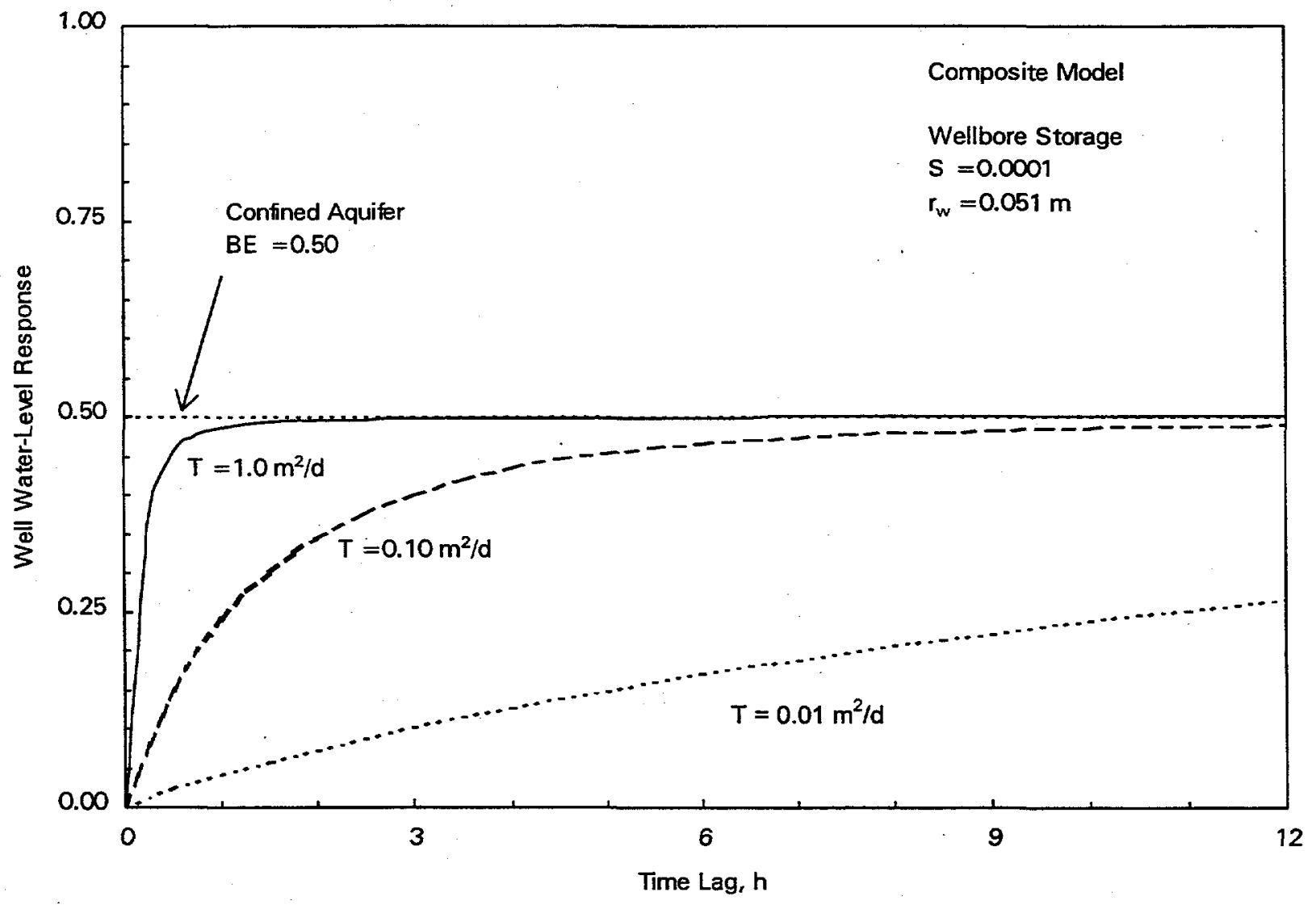

Figure 3.8. Composite Diagnostic Response Function for Wellbore-Storage/Confined Aquifer Model 


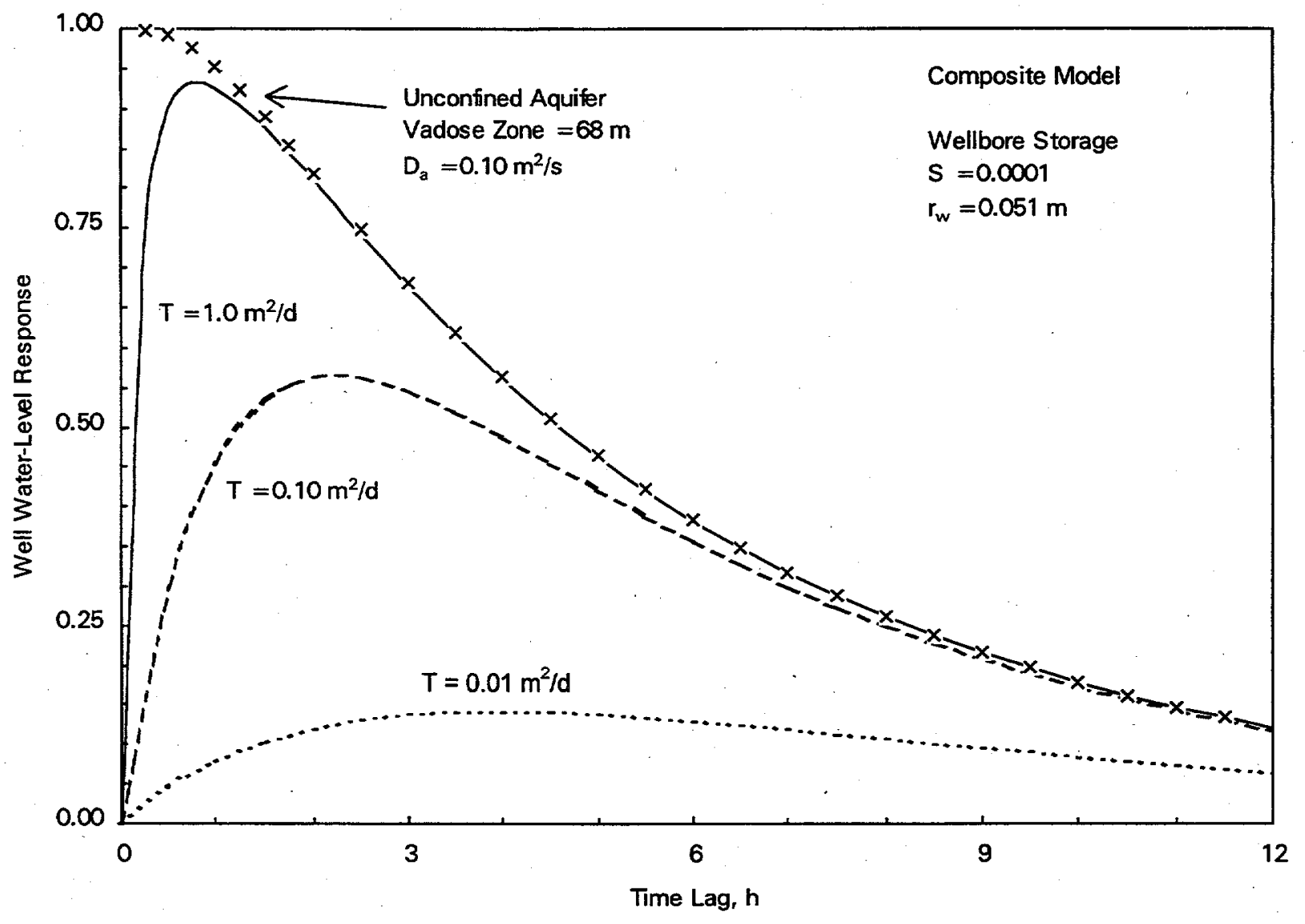

Figure 3.9. Composite Diagnostic Response Function for Wellbore-Storage/Unconfined Aquifer Model 


\subsection{Barometric Removal Techniques}

Water-level measurements obtained from monitoring wells are commonly used for delineating areal groundwater-flow direction and velocity. They are also used in aquifer test analysis for estimating the hydraulic properties of aquifers. Water-level measurements obtained from open (to the atmosphere) wells, however, can be significantly affected by transient variations in atmospheric pressure, causing erroneous calculations of hydraulic head and having adverse effects on aquifer test analysis results. How barometric effects are accounted for is dependent on the characterization application.(i.e., groundwaterflow pattern delineation or aquifer test analysis).

For flow-pattern delineation, the objective is to determine the areal total head distribution within the aquifer. As discussed in Section 3.0, if the diagnostic barometric response for a well is clearly unaffected by wellbore-storage/skin conditions, then well water-level measurements can be used directly for calculating aquifer total head conditions at the time of measurement. Total aquifer head can be calculated from well measurements by adding the incremental change of atmospheric pressure at the time of measurement (i.e., from the reference site atmospheric pressure value) directly to the observed water-level elevation measurement. For Hanford Site applications, it is recommended that the long-term, average, atmospheric pressure reading $(10.087 \mathrm{~m}$ ) at the Hanford Meteorology Station be used as the reference value. As presented in Section 3.0, analysis of the total head distribution (and not well water-level elevation) provides the basis for determining groundwater-flow characteristics within the aquifer. An example, using the recommended analysis procedure for determination of groundwater-flow direction and hydraulic gradient in low-gradient areas, is provided in Section 5.0.

For aquifer test analysis, the change in hydraulic head versus time imposed by a hydrologic test (as measured in wells) can be analyzed to provide estimates of hydraulic properties. Inherent in aquifer test analysis is the assumption that any extraneous stress effects that influence head measurements obtained during hydrologic testing be effectively removed. As indicated previously, barometric effects can exert a significant impact on well water-level measurements and hydraulic head conditions within the aquifer. These effects can become particularly important in the analysis of long-duration hydrologic tests, such as constant-rate pumping. Removal of barometric effects is dependent on the diagnostic response model exhibited by the well/aquifer system with different removal methods recommended for confined and unconfined aquifers, as well as for those exhibiting composite model-response behavior.

The removal of barometric effects from well water-level measurements has been examined by several investigators. Because of the frequency characteristics of barometric pressure fluctuations (e.g., diurnal), some removal techniques have focused on frequency-based methods (e.g., Chien et al. 1986; Rojstaczer 1988; Quilty and Roeloffs 1991). However, as noted by Furbish (1991), the application of frequencydomain removal methods for well measurements is not analytically straightforward. For this reason, more direct methods for predictive/removal of barometric effects are examined in this report. A detailed discussion of the various barometric removal methods for confined and unconfined aquifer systems is presented below. 


\subsection{Confined Aquifers}

Because of the instantaneous transmission of atmospheric pressure effects within confined aquifers, removal techniques for barometric fluctuations within these systems are generally simple and have been discussed in detail previously in the literature (e.g., Clark 1967). Although barometric fluctuations represent an areal, blanket stress applied to a confined aquifer, the magnitude of formation pressure change at any particular locality is a function of the degree of aquifer confinement, rigidity of the aquifer matrix, and specific weight of groundwater.

Generally, stresses imposed by hydrologic tests exceed those imposed by atmospheric pressure fluctuations on the aquifer. The removal of barometric effects, however, is expected to be more important for hydrologic tests of long duration (e.g., pumping test recovery) and/or tests with low-magnitude hydraulic responses (e.g., slug interference tests).

Briefly stated, the removal of barometric fluctuations from hydrologic test data requires the following steps:

1. collect test site atmospheric pressure values and associated aquifer formation pressure values for a pre- or post-test baseline period, during which no other extraneous stresses are imposed on the well/aquifer system

2. determine the long- and short-term barometric efficiencies for the baseline well data record, using the linear-regression algorithms outlined in Rasmussen and Crawford (1997) for distinguishing between confined and unconfined aquifer behavior

3. perform diagnostic barometric response analysis of the baseline well data record using the multipleregression convolution method described by Rasmussen and Crawford (1997) to distinguish between aquifer or composite well/aquifer model behavior

4. depending on the operative well/aquifer-response model, remove barometric induced changes from the test data record using either multiple-regression deconvolution or the Clark (1967) method.

For aquifer test applications, it is recommended that a minimum of 5 days of pre- and/or post-test baseline data be collected for long-term, $\mathrm{BE}_{\text {long, }}$ and short-term, $\mathrm{BE}_{\text {short }}$ calculations. Test data recording frequencies between 10 to $60 \mathrm{~min}$ have been observed to produce consistent $\mathrm{BE}$ calculations for baseline collection periods for Hanford Site conditions. As noted in Rasmussen and Crawford (1997), long-term regression is determined by direct linear regression of the observed barometric and well water-level data, while short-term regression can be determined by linear-regression analysis of the observed changes in barometric and well water-level data using the Clark (1967) method. (Note: A brief discussion of BE calculation using the Clark 1967 method is presented in Section 3.1.) A comparison of the linear-regression slopes (i.e., BE values) for the two methods is indicative of either confined or unconfined aquifer behavior. As indicated by Rasmussen and Crawford (1997) for confined aquifer situations, wherein wellbore storage and well skin are not significant, no difference in the calculated $\mathrm{BE}_{\text {long }}$ and $\mathrm{BE}_{\text {short }}$ 
linear-regression relationships is expected, while for unconfined aquifers, $B E_{\text {short }}>\mathrm{BE}_{\text {long. }}$. For cases where wellbore storage/well skin are evident, $\mathrm{a} \mathrm{BE}_{\text {long }}>\mathrm{BE}_{\text {short }}$ relationship for composite well/confined aquifer systems is exhibited.

To evaluate or identify more fully the operative barometric response model (i.e., between aquifer or composite well/aquifer behavior), analysis of the baseline well data record using the multiple-regression method described by Rasmussen and Crawford (1997) is recommended. As discussed in Section 3.0 and shown in Figure 3.1, the diagnostic barometric response pattern for a confined aquifer model is distinguished by a constant well-response function for a step in pressure for all time lags. This constancy in barometric response is attributed to the lack of dependence on lagged barometric response (i.e., barometric effects are applied "instantaneously" both at the well and to the aquifer system). A composite well/confined aquifer model would display a low dependence for small time-lag values, progressively increasing and becoming constant with larger time lags as shown in Figure 3.8.

Once the operative well/aquifer-response model has been identified, barometric induced changes within the hydrologic test data can be removed, using either multiple-regression deconvolution (for composite response systems) or the Clark (1967) method (for simple, confined aquifer models). Removal of barometric effects during testing requires that a reference atmospheric pressure be used to correct the aquifer test data record. For most hydrologic test applications, the observed atmospheric pressure immediately prior to test initiation is used as the reference atmospheric pressure. Examples and discussions of removing barometric pressure effects from hydrologic test data for confined aquifers on the Hanford Site using the Clark (1967) method are provided in Spane (1992, 1993). An example of the corrective procedure for test data that exhibit delayed well-response characteristics (i.e., for unconfined aquifer or composite well/aquifer models) is provided below.

\subsection{Unconfined Aquifers}

Because water-level measurements from unconfined aquifer wells exhibit variable time-lagged responses to barometric fluctuations (i.e., the well water-level response is dependent on the duration/ magnitude of the barometric pressure change and vadose zone characteristics), the removal procedure is not as simple or straightforward as for wells monitoring confined aquifers. The initial steps for removing barometric effects from unconfined aquifer hydrologic test data are the same as steps 1,2, and 3 in Section 4.1 for confined aquifers. Linear- and multiple-regression diagnostic methods are used to verify the operative barometric response model. Then, one of the methods discussed below can be used to remove barometric effects from head measurements collected during hydrologic tests. The removal method selected is dependent on the type of response model exhibited (e.g., unconfined aquifer or composite wellbore storage/unconfined aquifer) and characteristics of the monitoring system employed. The three removal methods discussed include a closed-well system, multiple regression, and vadose zone model, followed by a brief comparison of the three methods.

\subsubsection{Closed-Well System}

A closed-well system provides a direct means of eliminating the effects of wellbore storage caused by direct atmospheric pressure fluctuations applied within open-well facilities. As previously discussed, the 
presence of wellbore-storage effects complicates the barometric removal procedure. Eliminating this component of a composite well/aquifer barometric response facilitates the removal with either multipleregression deconvolution or the vadose zone model (discussed in the following sections). Closed-well system pressures measured with an absolute pressure gauge provide total head values within the aquifer and represent the water-table elevation and the component of atmospheric pressure that is transmitted through the vadose zone to the water-table surface. For a static water-table elevation condition within an unconfined aquifer, closed-well system measurements would vary only as a result of the time-lagged response to atmospheric pressure changes occurring at land surface. As described in Section 3.2, the magnitude and time-lag characteristics of atmospheric pressure transmission to the water-table surface are a function of the pneumatic diffusivity, moisture content, thickness, and compressibility of the gas phase within the vadose zone.

To evaluate the variability of total head measurements occurring within the Hanford Site unconfined aquifer, data were collected over a 4-week period (August 6 - September 3, 1998) using a Westbay Instruments, Inc. closed-well monitoring system at well 699-43-42K. This closed-well installation provides access to four separate depth intervals using a Westbay Instruments Multiport (MP ${ }^{\mathrm{TM}}$ ) system. A detailed description of the test facility is presented in Gilmore (1989) and Gilmore et al. (1991). Previous hydrologic characterization tests conducted using this facility are presented in Spane and Thorne (1995) and Spane et al. (1996). The lower three ports were monitored during this period and provided nearly identical total head measurement patterns. The measurement point depths of the three zones were located approximately $0.5,4.5$, and $9 \mathrm{~m}$ below the water table, which at that time was $\sim 53 \mathrm{~m}$ below ground surface. Each of the individual monitoring intervals was isolated with bentonite grout placed in the annular area outside the well. A Westbay Modular Subsurface Data Acquisition System (MOSDAX $^{\mathrm{TM}}$ ) was used to record monitoring zone pressures simultaneously, as well as test site atmospheric pressure conditions. The test data were collected at 10-min intervals, with the objective of providing a data set of total head within the aquifer, which could be used to assess barometric removal techniques in support of aquifer test applications. A discussion and demonstration of the barometric removal techniques are provided below.

The monitoring system employed at the facility provides a closed-well system at the point of pressure measurement, thereby eliminating the impact of wellbore-storage effects on total head measurements. If a monitoring well is closed or isolated above the water table (e.g., with a surface wellhead system), the compressibility of the closed air (gas) column above the water table will cause additional time delay and possibly dampen downhole pressure measurements in comparison to actual aquifer conditions.

Figure 4.1 shows the variability of total head at well $699-43-42 \mathrm{~K}$, as recorded for the middle closedwell monitoring interval (zone 3), located $\sim 4.5 \mathrm{~m}$ below the water table. As shown, an apparent high visual correlation between total head and site atmospheric pressure conditions is evident, suggesting a relatively rapid transmission of the atmospheric pressure fluctuation signal through the 53-m vadose zone thickness. For comparison purposes, the theoretical open-well water-level elevation response (i.e., if the well were not closed in) is also shown. The well water-level response was calculated (assuming no wellbore-storage effects) by subtracting the atmospheric pressure change occurring at land surface directly from the total head measurement obtained for the monitoring interval, as was discussed previously. As indicated in Figure 4.1, the well water-level elevation response exhibits considerably less 


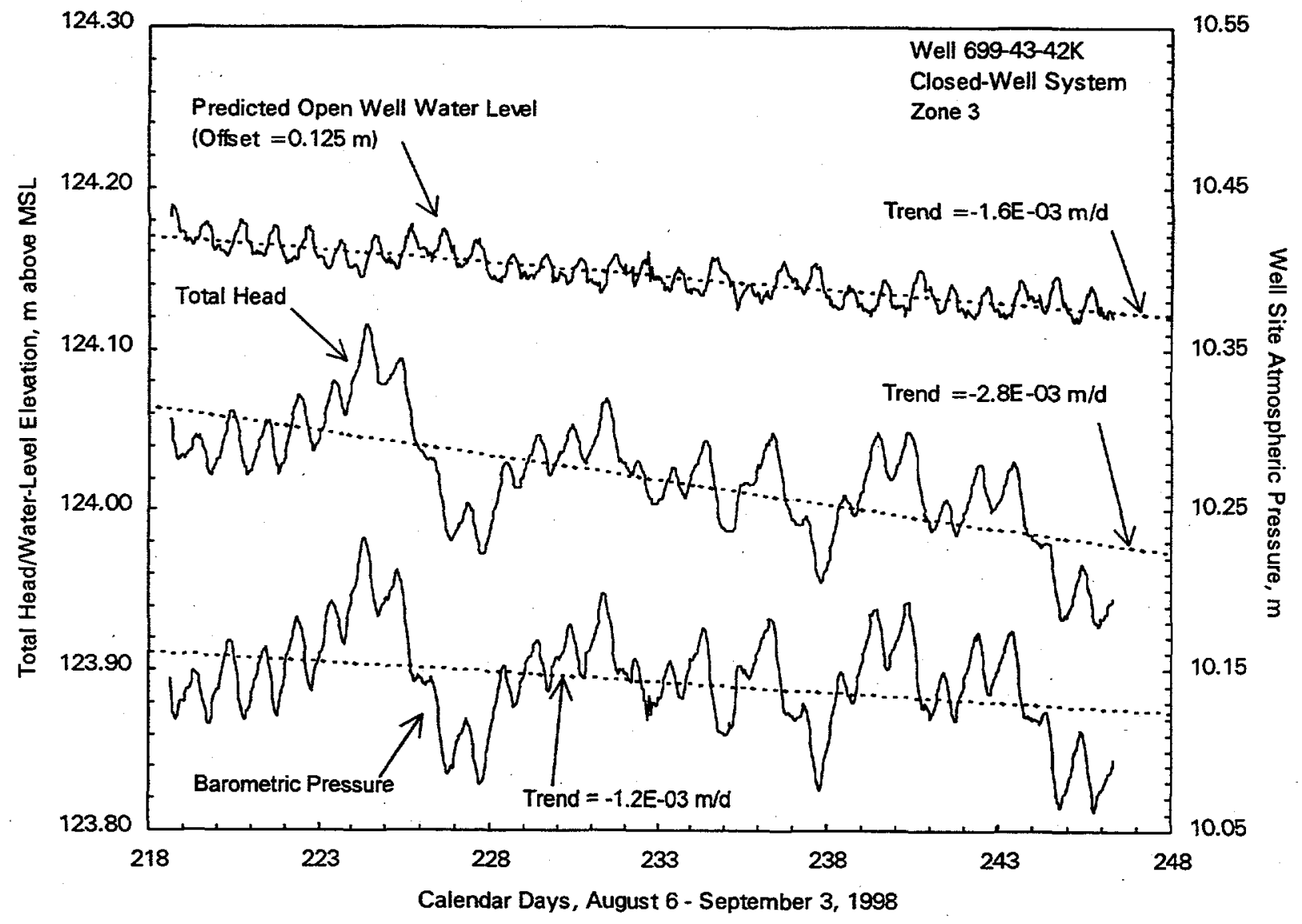

Figure 4.1. Total Head and Atmospheric Pressure Measurements for Well 699-43-42K Zone 3 (closed-well system), August 6 - September 3, 1998

variability and is a poor indicator of total head variability occurring within the aquifer. This lack of well water-level response is attributed to the rapid vadose zone transmission of the atmospheric pressure, which lessens the impact of atmospheric pressure changes applied immediately to the open well.

Linear-regression analysis of the observed data indicates that the total head trend was approximately twice that indicated for the barometric pressure record $(-2.8 \mathrm{E}-03$ versus $-1.2 \mathrm{E}-03 \mathrm{~m} / \mathrm{d})$. This suggests that a background water-table trend was prevalent during the 4-week period of observation. The observed background negative trend in total head $(-1.6 \mathrm{E}-03 \mathrm{~m} / \mathrm{d})$ is consistent with decommissioning activities at the nearby B Pond recharge facility, and this declining head trend has been observed at other surrounding monitoring well locations.

\subsubsection{Multiple-Regression Techniques}

Multiple-regression deconvolution techniques can be utilized to remove barometric effects from hydrologic test data that exhibit either aquifer or composite wellbore-storage/aquifer-response characteristics. To demonstrate the removal procedure, the 4-week total head record for zone 3 (shown in Figure 4.1) was analyzed using the multiple-regression technique described in Rasmussen and Crawford 
(1997). Changes in observed total head, $\Delta H_{t}$, versus associated time-lagged barometric pressure changes, $\Delta B$, were used in the regression rather than observed $\mathrm{H}_{\mathrm{t}}$ versus observed $\mathrm{B}$. Figure 4.2 shows the diagnostic barometric response pattern obtained from the observed total head multiple-regression analysis for all three monitoring zones. The total head analysis results are consistent with an unconfined aquifer barometric response model, as shown in Figure 3.2. The rapid transmission of barometric pressure through the vadose zone at this site is evident by the larger head-response dependence for early time-lag periods.

A comparison of the monitoring zone-response patterns indicates nearly identical characteristics for zones 3 and 4, the deepest monitoring zones. The reason for the slightly time-lagged response for zone 2 , which suggests additional wellbore storage, is not completely understood. The previous hydrologic testing activities (see Spane and Thorne 1995 and Spane et al. 1996) at the site may be responsible for incorporating air/gas at the top of the unconfined aquifer as a result of the lowering and subsequent recovery of the water-table surface. This could possibly explain the "storage-" induced, time-lagged response observed by the top monitoring zone, which is in proximity to the current water-table surface (i.e., within $0.5 \mathrm{~m}$ ).

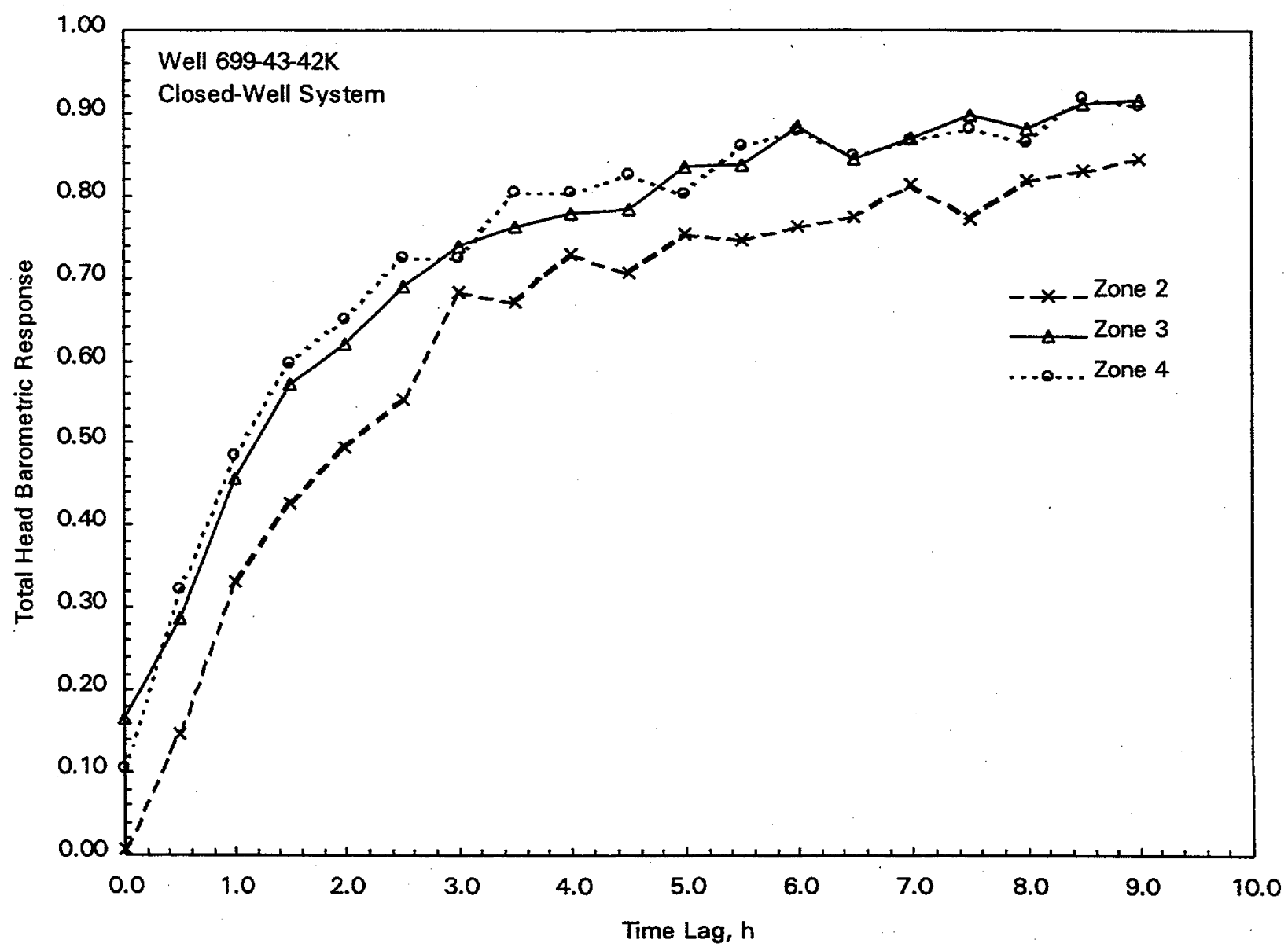

Figure 4.2. Total Head Barometric Response Patterns for Well 699-43-42K Zones 2, 3, and 4 
To demonstrate the "goodness-of-fit" of the regression analysis, the predicted total head response was calculated for zone 3 , based on the multiple-regression coefficients determined for 0.5 -h time lags, for a maximum 9-h period (Table 4.1). Figure 4.3 shows the comparative match between observed and predicted total head using the multiple-regression method. As indicated, a very close match was obtained for zone $3\left(r^{2}=0.99\right)$. Similar matches were also obtained for zones 2 and 4 (not shown).

Given the high correspondence between predicted and observed total head, it is expected that adverse barometric effects could be effectively removed from hydrologic test data. To remove the effects of the barometric fluctuations, a total head correction was calculated by summing the products of the previously

Table 4.1. Multiple-Regression Analysis Results for Closed- and Open-Well System Measurements Obtained at Well 699-43-42K

\begin{tabular}{|c|c|c|c|c|c|c|}
\hline \multirow[b]{3}{*}{$\begin{array}{l}\text { Time } \\
\text { Lag, h }\end{array}$} & \multicolumn{6}{|c|}{ Barometric Regression Analysis } \\
\hline & \multicolumn{2}{|c|}{$\begin{array}{c}\text { Total Head } \\
\text { Closed-Well System }^{(\mathrm{a})}\end{array}$} & \multicolumn{2}{|c|}{$\begin{array}{c}\text { Total Head } \\
\text { Open-Well System }^{(b)}\end{array}$} & \multicolumn{2}{|c|}{$\begin{array}{l}\text { Well Water Level } \\
\text { Open-Well System } \\
\text { (c) }\end{array}$} \\
\hline & $\begin{array}{l}\text { Regression } \\
\text { Coefficient }\end{array}$ & $\begin{array}{c}\text { Regression } \\
\text { Coefficient Sum }^{\text {(d) }}\end{array}$ & $\begin{array}{l}\text { Regression } \\
\text { Coefficient }\end{array}$ & $\begin{array}{c}\text { Regression } \\
\text { Coefficient Sum }^{(\mathrm{d})}\end{array}$ & $\begin{array}{l}\text { Regression } \\
\text { Coefficient }\end{array}$ & $\begin{array}{c}\text { Regression } \\
\text { Coefficient Sum }^{(\mathrm{d})}\end{array}$ \\
\hline 0.0 & 0.1652 & 0.1652 & 0.1329 & 0.1329 & -0.8676 & 0.8676 \\
\hline 0.5 & 0.1216 & 0.2868 & 0.1576 & 0.2905 & 0.1587 & 0.7089 \\
\hline 1.0 & 0.1700 & 0.4568 & 0.0923 & 0.3828 & 0.0910 & 0.6179 \\
\hline 1.5 & 0.1142 & 0.5710 & 0.1362 & 0.5190 & 0.1374 & 0.4805 \\
\hline 2.0 & 0.0482 & 0.6192 & 0.0725 & 0.5915 & 0.0729 & 0.4076 \\
\hline 2.5 & 0.0698 & 0.6890 & 0.0900 & 0.6815 & 0.0879 & 0.3197 \\
\hline 3.0 & 0.0505 & 0.7395 & 0.0038 & 0.6853 & 0.0043 & 0.3154 \\
\hline 3.5 & 0.0226 & 0.7621 & 0.0693 & 0.7546 & 0.0714 & 0.2440 \\
\hline 4.0 & 0.0176 & 0.7797 & 0.0137 & 0.7683 & 0.0120 & 0.2320 \\
\hline 4.5 & 0.0043 & 0.7840 & 0.0067 & 0.7750 & 0.0082 & 0.2238 \\
\hline 5.0 & 0.0496 & 0.8336 & 0.0479 & 0.8229 & 0.0473 & 0.1765 \\
\hline 5.5 & 0.0041 & 0.8377 & 0.0091 & 0.8320 & 0.0076 & 0.1689 \\
\hline 6.0 & 0.0466 & 0.8843 & 0.0255 & 0.8575 & 0.0270 & 0.1419 \\
\hline 6.5 & -0.0394 & 0.8449 & -0.0146 & 0.8429 & -0.0151 & 0.1570 \\
\hline 7.0 & 0.0244 & 0.8693 & 0.0460 & 0.8889 & 0.0462 & 0.1108 \\
\hline 7.5 & 0.0279 & 0.8972 & -0.0544 & 0.8345 & -0.0547 & 0.1655 \\
\hline 8.0 & -0.0159 & 0.8813 & 0.0061 & 0.8406 & 0.0052 & 0.1603 \\
\hline 8.5 & 0.0292 & 0.9105 & 0.0289 & 0.8695 & 0.0290 & 0.1313 \\
\hline 9.0 & 0.0056 & 0.9161 & 0.0291 & 0.8986 & 0.0303 & 0.1010 \\
\hline \multicolumn{7}{|c|}{$\begin{array}{l}\text { (a) Closed-system data collected between August } 6 \text { and September 3,1998. } \\
\text { (b) Open-system data collected between September } 7 \text { and 30,1998. } \\
\text { (c) Calculated water-level elevation data for September } 7 \text { and 30, } 1998 . \\
\text { (d) Absolute values for regression coefficient summation. }\end{array}$} \\
\hline
\end{tabular}




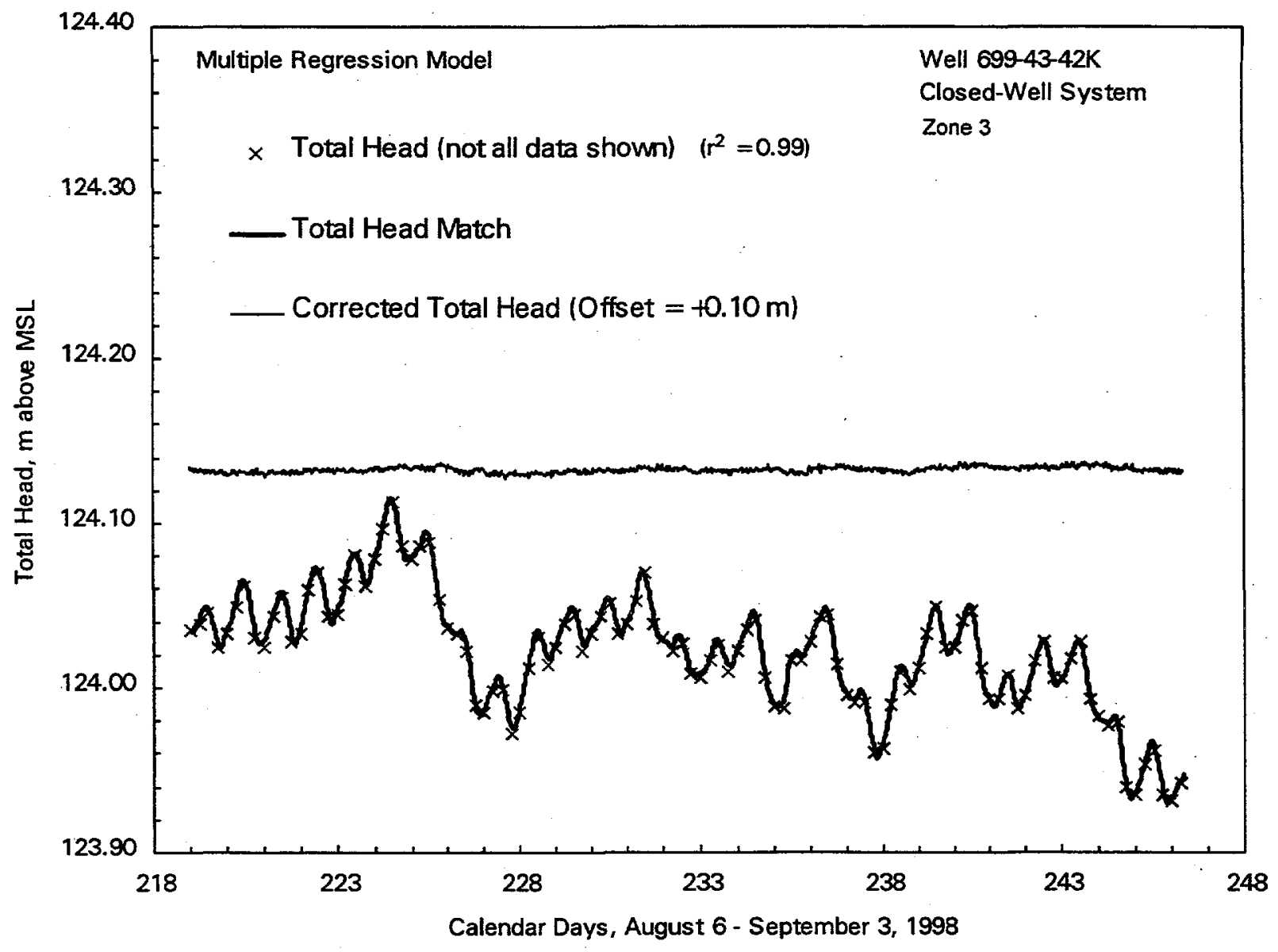

Figure 4.3. Multiple-Regression Match and Barometric Correction of Closed-Well Total Head Response for Well 699-43-42K Zone 3

determined regression coefficients multiplied by their respective time-lagged $\Delta B$ values. The summed head correction was then subtracted from the observed total head values. The comparison of observed and corrected total head values is shown in Figure 4.3; essentially all of the observed total head variability caused by barometric fluctuations during the time period was eliminated. This suggests that the significant effects of barometric fluctuations on total head conditions within the aquifer that would occur during hydrologic tests conducted at the site could be effectively removed using a closed-well system and multiple-regression deconvolution techniques.

As discussed in Section 4.1, closed-well systems provide a means of eliminating wellbore-storage/ skin effects from open-well system measurements. The only differences, then, between total head measurements obtained between open- and closed-well systems are the delayed effects caused by wellborestorage effects. In an effort to evaluate any differences between open- and closed-well measurements, the pumping port was opened for monitoring zone 3 , and total head measurements were recorded with the same absolute pressure probe suspended within the open-well monitoring system. Figure 4.4 shows the open-well system response for the period September $7-30,1998$. As indicated, a similarly high visual 


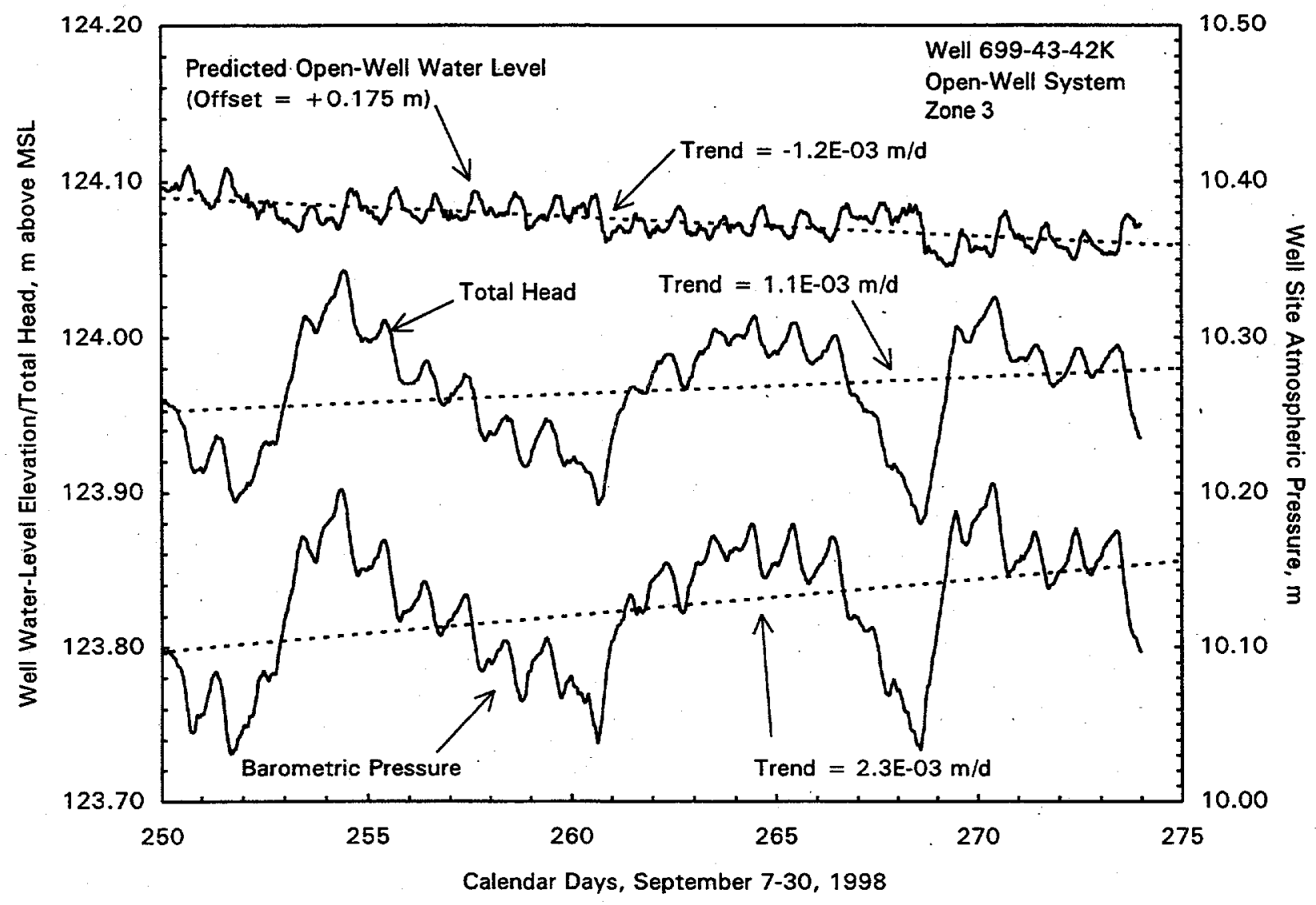

Figure 4.4. Total Head and Atmospheric Pressure Measurements for Well 699-43-42K Zone 3 (open-well system), September 7 - 30, 1998

correspondence between total head and barometric pressure fluctuations was exhibited. During this period, a positive linear trend in barometric pressure $(2.3 \mathrm{E}-03 \mathrm{~m} / \mathrm{d})$ caused an associated positive trend within the observed total head $(1.1 \mathrm{E}-03 \mathrm{~m} / \mathrm{d})$. The negative background trend $(1.2 \mathrm{E}-03 \mathrm{~m} / \mathrm{d})$, as reflected for the theoretical open-well water-level elevation plot, is comparable to the $1.6 \mathrm{E}-03-\mathrm{m} / \mathrm{d}$ trend calculated earlier for the closed-well measurement period.

To compare open- versus closed-well system characteristics, barometric response analysis was performed on the 23-day total head record shown in Figure 4.4. A comparative plot of the barometric response characteristics, based on $0.5-\mathrm{h}$ measurements, is provided in Figure 4.5 . The proximity and overall similarity in diagnostic plot patterns indicate that no significant wellbore-storage/skin effects are operative; however, the slight time-delay shift exhibited for most open-well measurements may be suggestive of some minor effects. The lack of dominant wellbore-storage effects for this open-well installation is expected, given the moderate $7.8-\mathrm{m}^{2} / \mathrm{d}$ aquifer transmissivity reported for the well site (Spane et al. 1996) and the small, open-well diameter $(0.019 \mathrm{~m})$. 


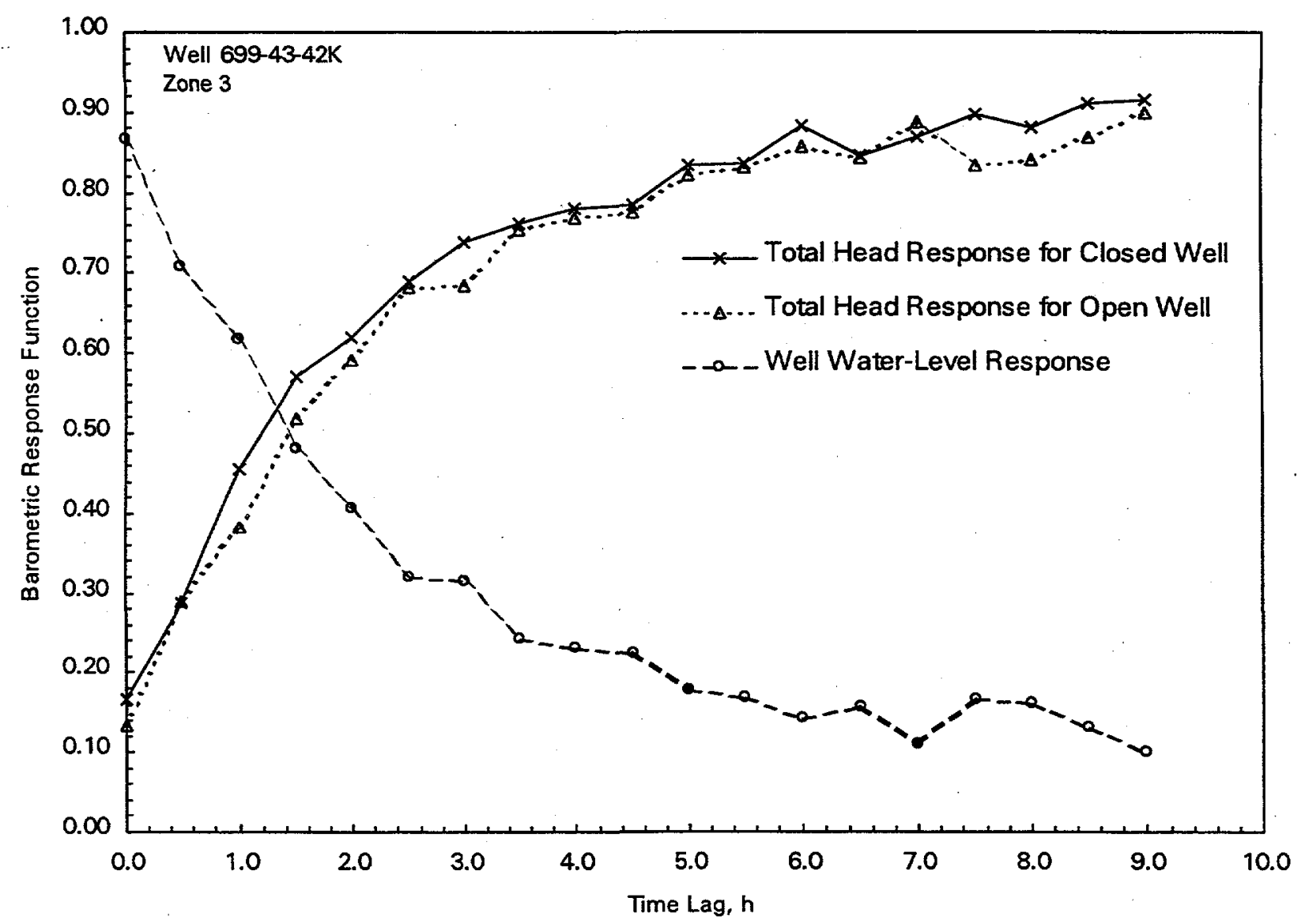

Figure 4.5. Comparison of Open Versus Closed System Total Head Barometric Response Patterns for Zone 3

For comparison purposes, the theoretical open-well water-level plot shown in Figure 4.4 was also analyzed. The total head and water-level barometric response plots shown in Figure 4.5 are both consistent with an unconfined aquifer model, as illustrated previously in Figures 3.1 and 3.2. A comparison summary of time-lag barometric response coefficients obtained from multiple-regression analysis of total head and theoretical water-level elevation data (for closed- and open-well systems) is given in Table 4.1.

A comparison of the observed and corrected total head values for the open-well system is shown in Figure 4.6. As for the closed-system comparison, essentially all of the observed total head variability caused by barometric fluctuations during the open-well configuration was eliminated using the multipleregression deconvolution techniques.

The open-well example examined above is not representative of standard monitoring well characteristics at the Hanford Site. Most Hanford Site monitoring wells have a larger well-casing radius (e.g., $0.051 \mathrm{~m}$ ) and commonly have the water table within the well-screen section. The larger well diameter 


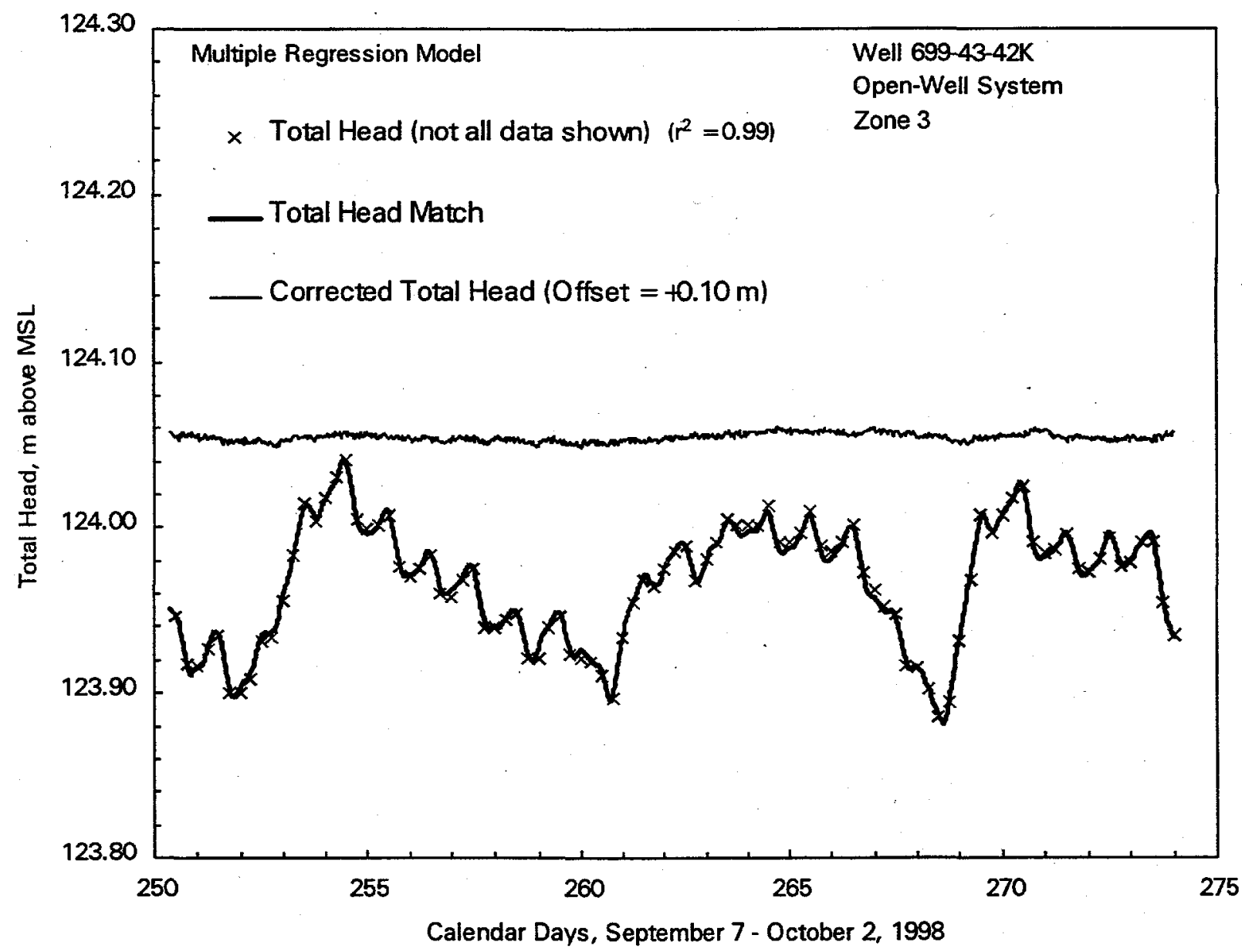

Figure 4.6. Multiple-Regression Match and Barometric Correction of Open-Well Total Head Response for Well 699-43-42K Zone 3

(wellbore-storage effects) and position of the water table (allowing direct transmission of the atmospheric pressure signal) would be expected to add additional complexity for removal of barometric pressure effects.

To assess the efficacy of barometric removal from test data obtained from standard-size, open-well systems at the Hanford Site, a 30-day period of test data obtained from well 299-E33-41 was examined using multiple-regression methods. The well site is located $\sim 3 \mathrm{~km}$ northwest of the previously discussed well $699-43-42 \mathrm{~K}$. The monitoring well was constructed in 1991, following State of Washington guidelines (WAC 1990). The well was constructed with a 5-m well screen (0.051-m I.D.), which was completed over the depth interval 74.6 to $79.6 \mathrm{~m}$ below ground surface. The water-table depth during the monitoring period was $\sim 77.7 \mathrm{~m}$ below ground surface. Well water-level response was recorded with a downhole differential (gauge) pressure transducer and data-logger system at a frequency of hourly readings between January 30 and March 1, 1999. Site barometric pressure readings were also recorded simultaneously with the water-level measurements. 
Figure 4.7 shows the well water-level elevation and calculated total head response, as compared to site barometric pressure readings. As shown, considerably more variability in water level and total head ( 0.14 and $0.40 \mathrm{~m}$, respectively) is evident for the well 299-E33-41 data record than was observed at well 699-43-42K. (Note: vertical scale for Figure 4.7 is twice that used in Figure 4.1.) The higher variability is attributed to the greater fluctuations in barometric pressure that occur during the winter and spring months. As shown, a slightly declining water-level trend $(-5.8 \mathrm{E}-04 \mathrm{~m} / \mathrm{d})$ was exhibited during the monitoring period. This is also reflected in the trend differences exhibited between barometric pressure and calculated total head. Diagnostic barometric response (multiple regression) analysis for the well water level and calculated total head is shown in Figure 4.8. The water-level and total head patterns displayed are consistent with an unconfined aquifer with wellbore-storage/skin effects. This composite model behavior is also suggested by the short- and long-term linear-regression/barometric efficiency relationships exhibited by the water-level data $\left(\mathrm{BE}_{\text {short }}=0.39 ; \mathrm{BE}_{\text {long }}=0.32\right)$. For unconfined aquifers, wellbore storage lessens the early time-lag response, making the short- and long-term BE closer in magnitude.

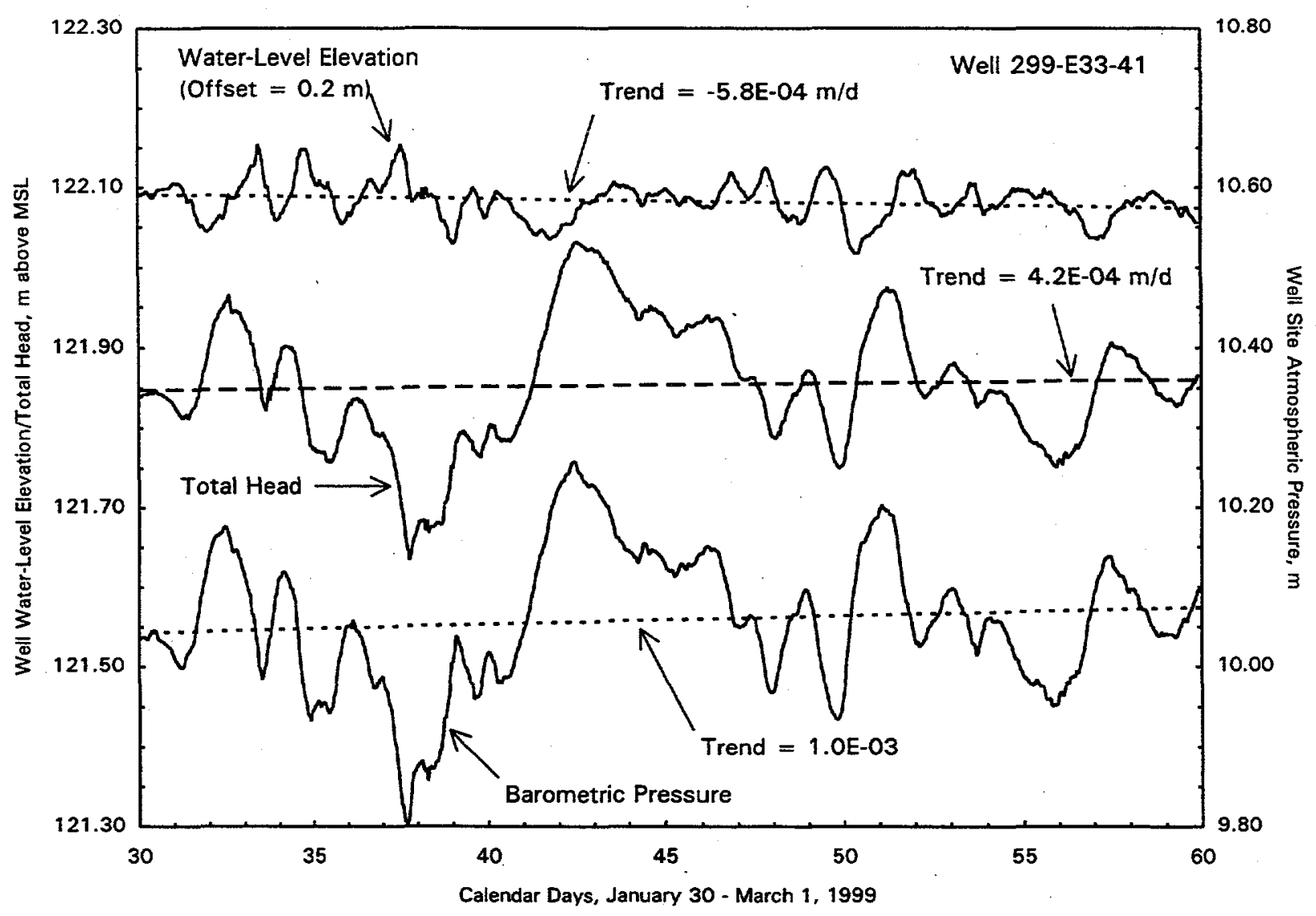

Figure 4.7. Observed Well Water-Level, Calculated Total Head, and Atmospheric Pressure Measurements for Well 299-E33-41, January 30 - March 1, 1999 


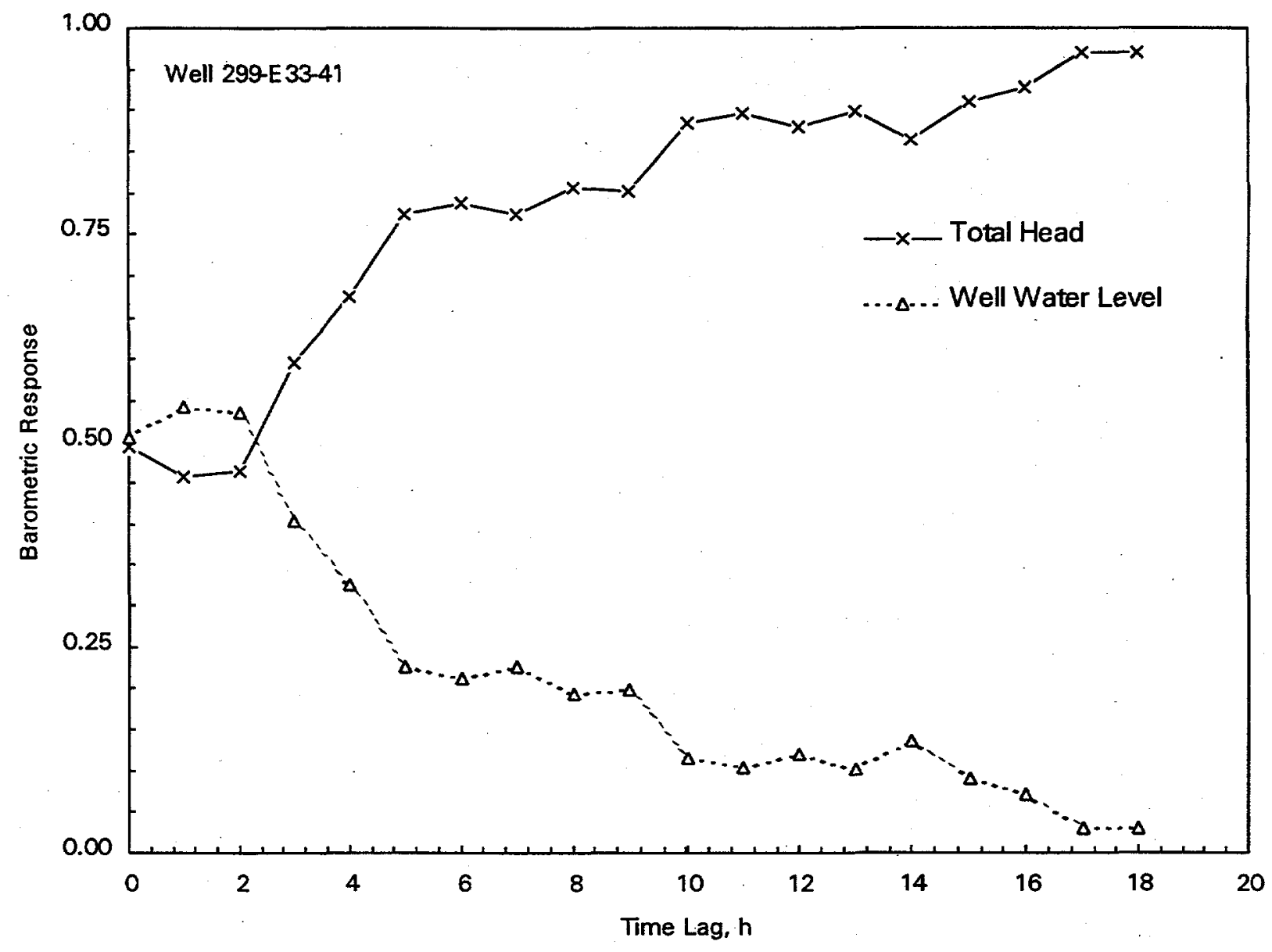

Figure 4.8. Comparison of Observed Well Water-Level and Calculated Total Head Barometric Response Patterns for Well 299-E33-41

Figure 4.9 shows the comparison of observed and corrected total head values using the multipleregression deconvolution techniques. As indicated, a significant amount of the observed total head variability caused by barometric fluctuations was eliminated using this removal method. While significantly reduced, the corrected total head for well 299-E33-41 exhibits more variability than for the closed-well installation at well $699-43-42 \mathrm{~K}$. The greater variability displayed is attributable to the presence of wellbore-storage/skin effects and the well-screen completion across the water table (allowing atmospheric pressure fluctuations to be imposed to the water table through the well).

\subsubsection{Vadose Zone Model}

The vadose zone model (WBAR program of Weeks 1979) was also used to analyze the observed closed- and open-well responses to evaluate its utility for removing barometric effects from total head and well water-level data. It should be noted that the original WBAR program only predicts open-well waterlevel response. To facilitate closed-well response prediction, Weeks, in a personal communication to the author in 1999, provided a modification to the program. 


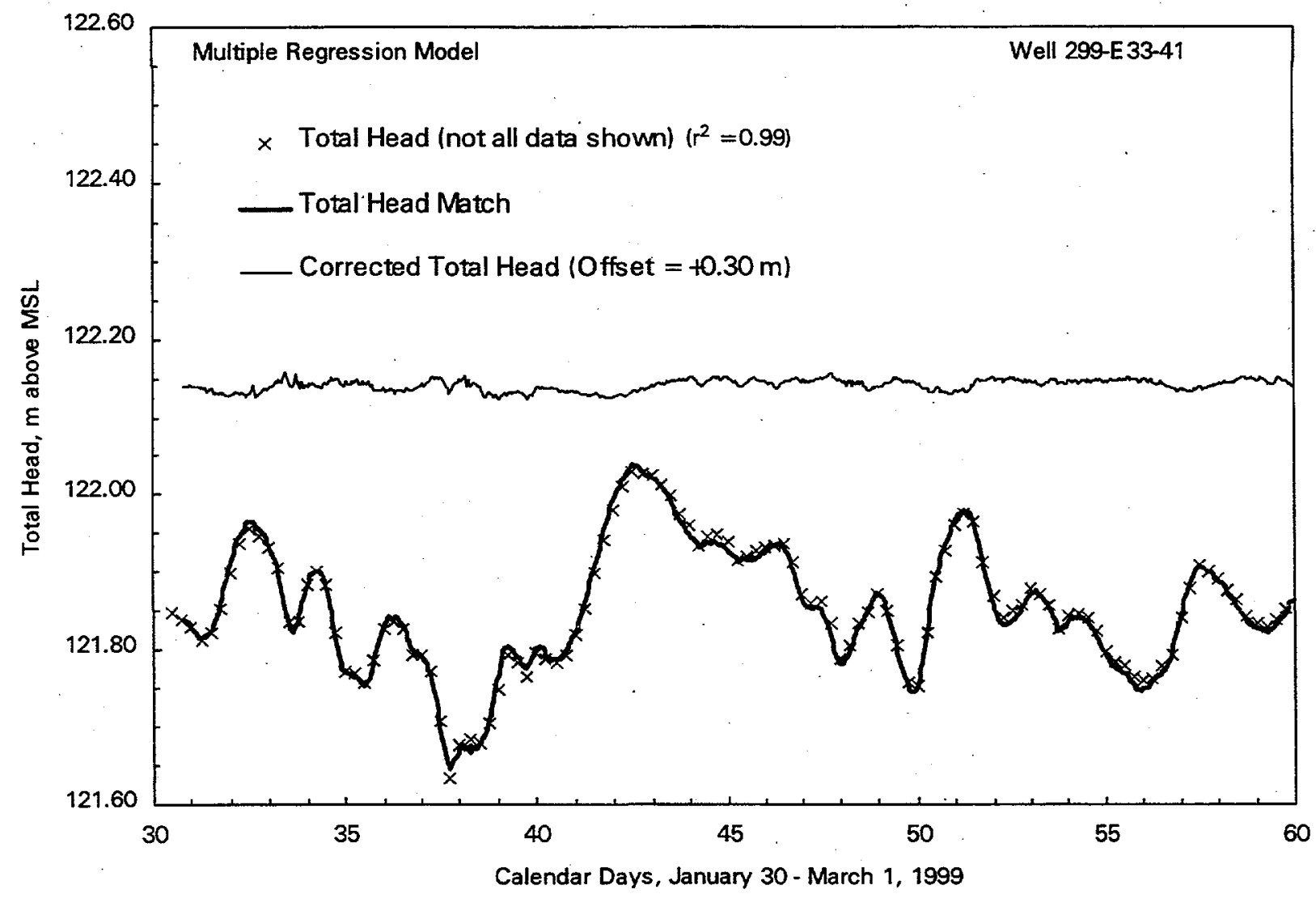

Figure 4.9. Multiple-Regression Match and Barometric Correction of Well Water-Level and Total Head Response for Well 299-E33-41

Figure 4.10 shows the results of matching the observed total head and theoretical water-level elevation obtained with the closed-well system for zone 3 in well 699-43-42K. As shown, the vadose zone model provides a close match to both total head and water-level data records. The final match was derived using a pneumatic diffusivity of $0.15 \mathrm{~m}^{2} / \mathrm{s}$ and a water-table trend of $-1.6 \mathrm{E}-03 \mathrm{~m} / \mathrm{d}$. The moderately high pneumatic diffusivity, obtained with vadose zone model analysis, is consistent with the previous regression analysis findings of relatively rapid transmission of the barometric signal to the water table (i.e., high dependence on early time lags).

Figure 4.11 shows the total head barometric correction plot developed using the vadose zone model. The vadose zone model results can be directly compared with the multiple-regression correction plot presented in Figure 4.3. A visual examination of the two methods indicates slightly more residual variability for the vadose zone model in comparison to the multiple-regression results. Similar findings were obtained when comparing model analysis results for the open-well data record (for both total head and water-level elevation) at well $699-43-42 \mathrm{~K}$.

To evaluate the applicability of this method for removing barometric effects from well measurements exhibiting wellbore-storage/skin effects and with well-screen completions across the water table, 


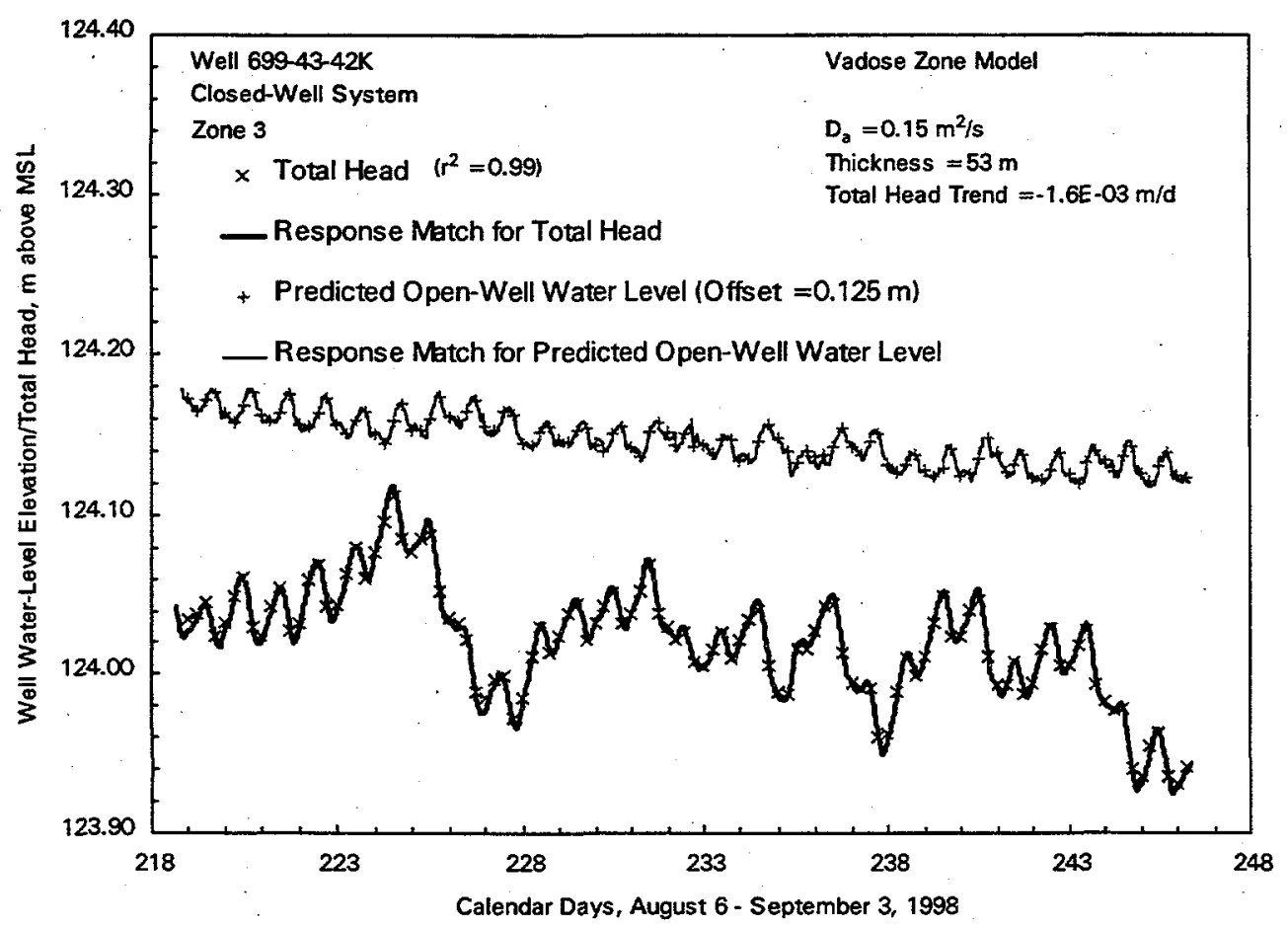

Figure 4.10. Vadose Zone Model Match of Well Water-Level Elevation and Total Head for Closed-Well 699-43-42K Zone 3

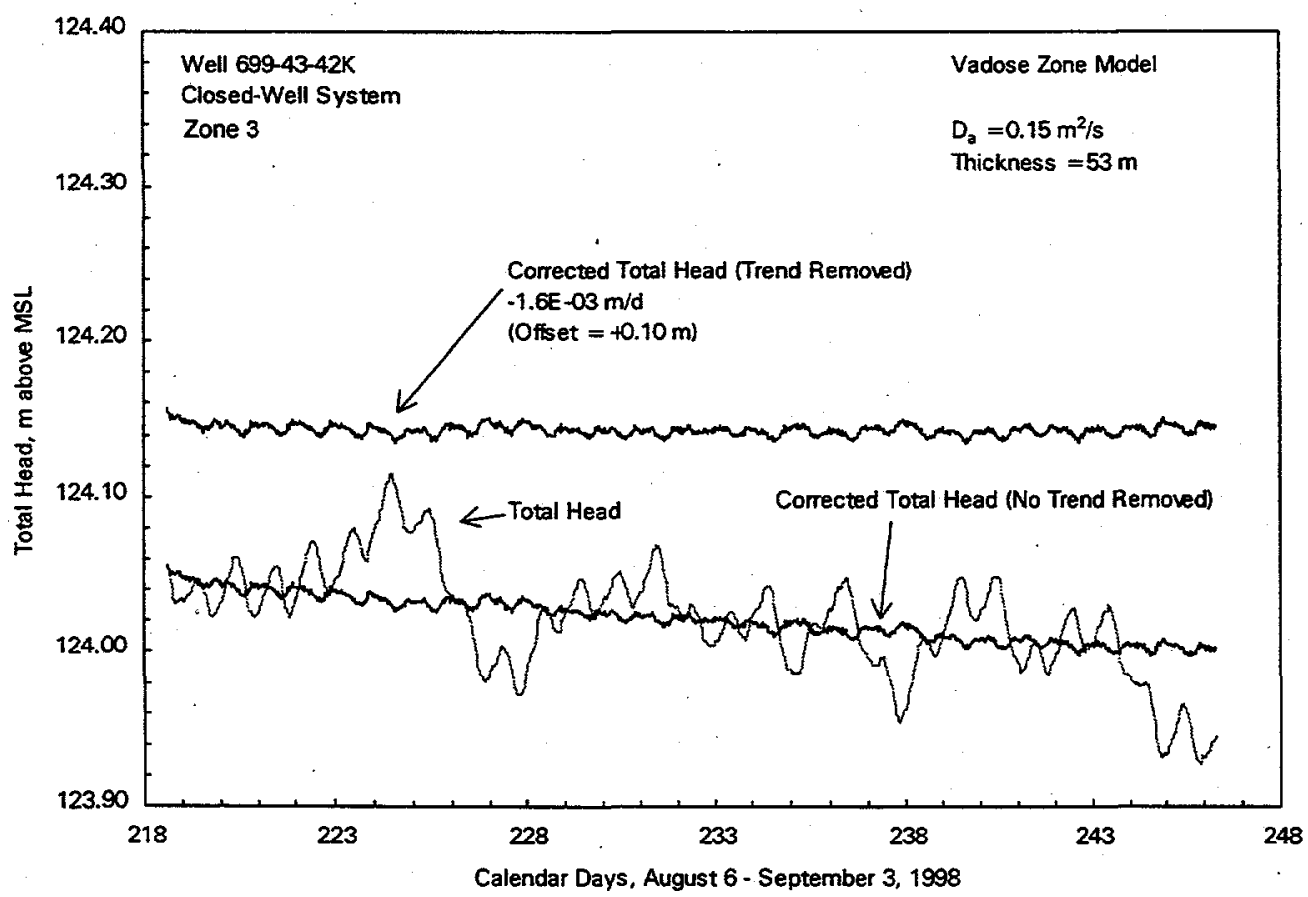

Figure 4.11. Vadose Zone Model Barometric Correction of Closed-Well Total Head Response for Well 699-43-42K Zone 3 
well 299-E33-41 response data (see Figure 4.7) were also analyzed using the vadose zone model. Figure 4.12 shows the results of matching the calculated total head and observed water-level elevation. As shown, the vadose zone model provides a close match for both total head and water-level data records. The final match was derived using a moderately high pneumatic diffusivity of $0.20 \mathrm{~m}^{2} / \mathrm{s}$ and a background water-table trend of $-5.8 \mathrm{E}-04 \mathrm{~m} / \mathrm{d}$. The pneumatic diffusivity value obtained with vadose zone model analysis is consistent with the previous regression analysis findings of relatively rapid transmission of the barometric signal to the water table (i.e., high dependence on early time lags) and is comparable with the vadose zone model value obtained for the nearby well $699-43-42 \mathrm{~K}$ site.

Figure 4.13 shows the total head barometric correction plot for well 299-E33-41, developed using the vadose zone model. These results can be directly compared with the multiple-regression correction plot presented in Figure 4.9. A visual examination of the two methods indicates more residual variability for the vadose zone model compared to the multiple-regression results. The greater variability is believed to be attributable to the effects of wellbore-storage/skin and the well-screen completion across the water table. Both of these well conditions are not accounted for within the vadose zone model.

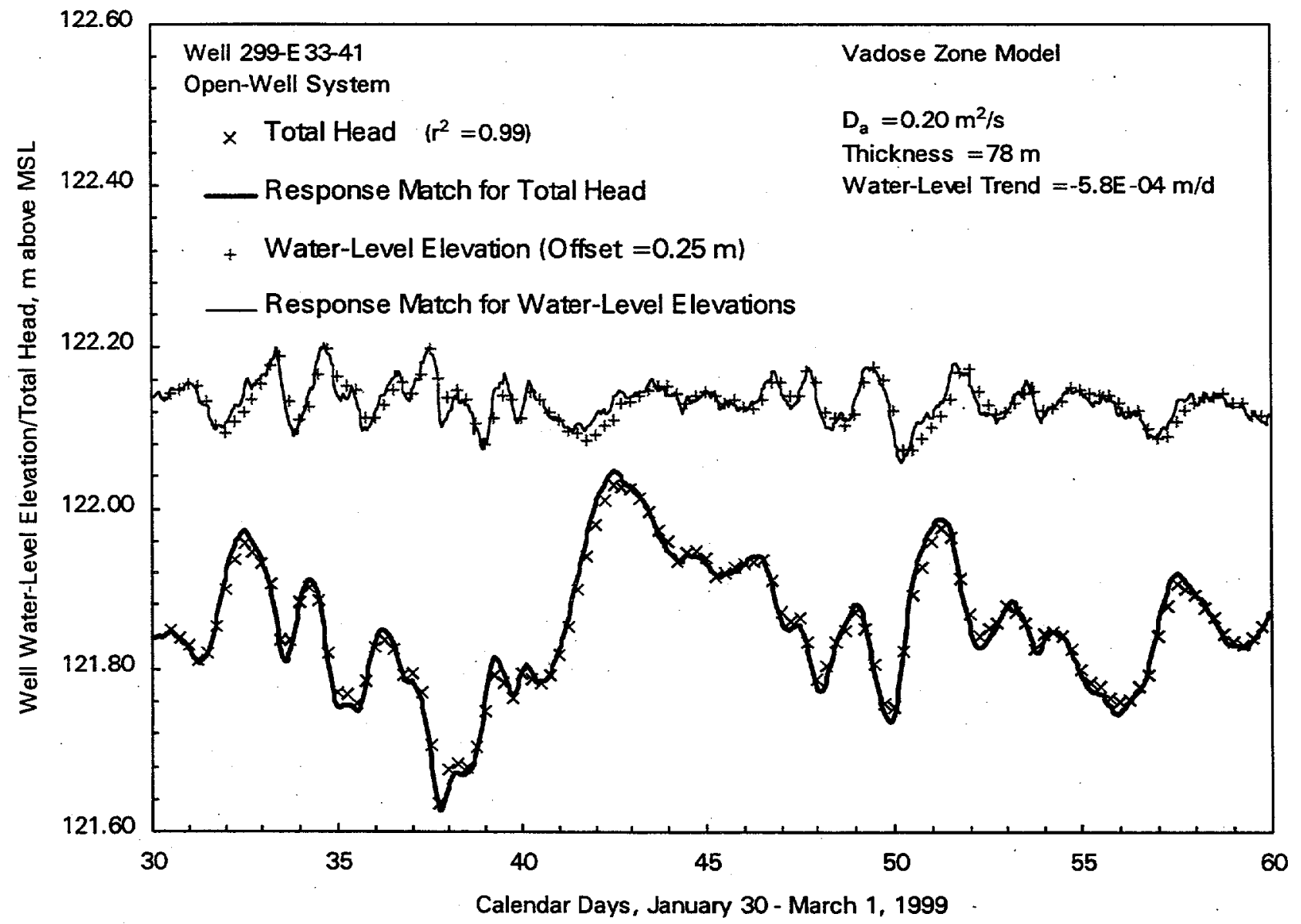

Figure 4.12. Vadose Zone Model Match of Well Water-Level Elevation and Total Head for Open-Well 299-E33-41 


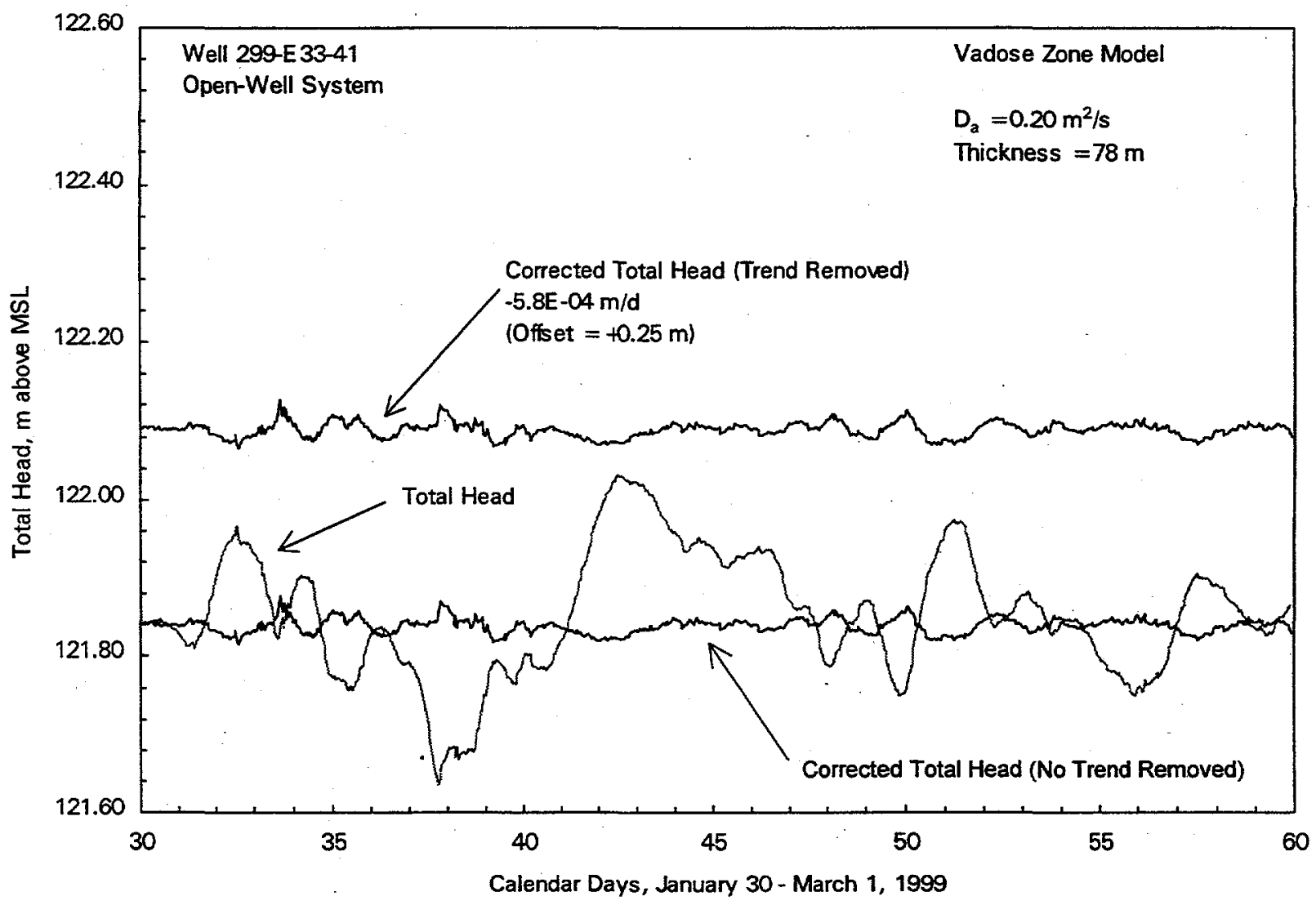

Figure 4.13. Vadose Zone Model Barometric Correction of Open-Well Total Head Response for Well 299-E33-41

\subsubsection{Removal Method Comparison}

Although the comparison of barometric removal methods is not fully comprehensive, a number of observations can be presented about their characteristics and application. Multiple-regression deconvolution techniques appear to have a wider application in removing barometric effects from various aquifer and composite well/aquifer-response systems. Because of this wider adaptability, higher quality correction results are likely. Multiple-regression methods, however, require longer baseline data periods to be effective, and quantitative characterization of the physical system properties controlling the barometric response cannot be directly determined by the matching analysis results.

In comparison, the vadose zone model can be applied with minimal baseline data, and physical system properties (e.g., pneumatic diffusivity, vadose zone thickness, background water-table trend) can be determined directly from the analysis. A weakness of the vadose zone model is its inability to account for wellbore-storage, well-skin, and specific boundary situations where the water table occurs within the well-screen section, allowing direct transmission of the atmospheric pressure signal to the water table through the well. Depending on the imposed severity of these local well and boundary conditions, removal of barometric effects from aquifer test data may be more limited using the vadose zone model. 


\subsection{Flow Direction and Hydraulic Gradient Determination}

The effects of barometric pressure fluctuations on well measurements were discussed in the preceding sections. Based on those discussions, it is apparent that atmospheric pressure fluctuations may cause temporal variations in groundwater-flow patterns within unconfined aquifers that exhibit low hydraulic gradient conditions and variable vadose zone properties (e.g., 200 East Area of the Hanford Site). This is due to the areal variation in transmission of atmospheric pressure to the water-table surface, which is part of the total hydraulic head governing groundwater flow.

For the determination of groundwater-flow direction and hydraulic gradient, total head (not well water-level elevation) should be the hydrologic parameter analyzed. For wells not exhibiting significant wellbore-storage/well-skin effects, total head can be calculated for confined and unconfined aquifers by adding the incremental barometric head (as compared to the reference barometric value) directly to the well water-level (elevation) measurement. Groundwater-flow direction and hydraulic gradient can be determined by standard trend-surface-fitting methods (or three-point problems) using total head measurements obtained from monitoring wells that meet the following criteria:

- are along the same hydrologic flow plane (i.e., planar potential surface)

- are measured close in time (e.g., within $12 \mathrm{~h} \mathrm{[1} \mathrm{to} 4 \mathrm{~h}$ for low-gradient areas])

- monitor similar depth intervals within the respective hydrogeologic unit

- display similar dynamic well-response characteristics (e.g., to barometric fluctuations)

- are not significantly affected by well-skin effects.

To evaluate the sensitivity of groundwater-flow direction and hydraulic gradient determinations within a low-gradient area, standard frequency (e.g., semiannual) Hanford Site water-level data were analyzed for wells used to monitor conditions surrounding the 216-B-63 Trench. This site was identified in Hartman (1999) as a low-hydraulic gradient area $(\sim 0.0003$ to $\sim 0.00005)$, which is difficult for determining groundwater-flow conditions. Figure 5.1 shows the monitoring well locations surrounding the 216-B-63 Trench.

To assess whether the uncertainty in groundwater-flow direction and hydraulic gradient could be reduced for this area, available monitoring wells were evaluated for quantitative analysis using some of the screening criteria listed above. Because detailed barometric response analysis data were not available for these wells, a general evaluation of the temporal water-level-response characteristics for wells completed at similar depth intervals was performed for data collected during calendar years 1996 through 1999. Figure 5.2 shows the general, similar, dynamic well-response characteristics exhibited for the seven monitoring wells selected for detailed groundwater-flow characterization. The overall declining water-level elevation trend pattern is consistent with cessation of wastewater disposal activities, both at the 216-B-63 Trench (in 1992) and surrounding areas (e.g., B Pond).

To facilitate quantitative determination of groundwater-flow direction and hydraulic gradient conditions, the commercially available WATER-VEL (In-Situ, Inc. 1991) software program was utilized. 


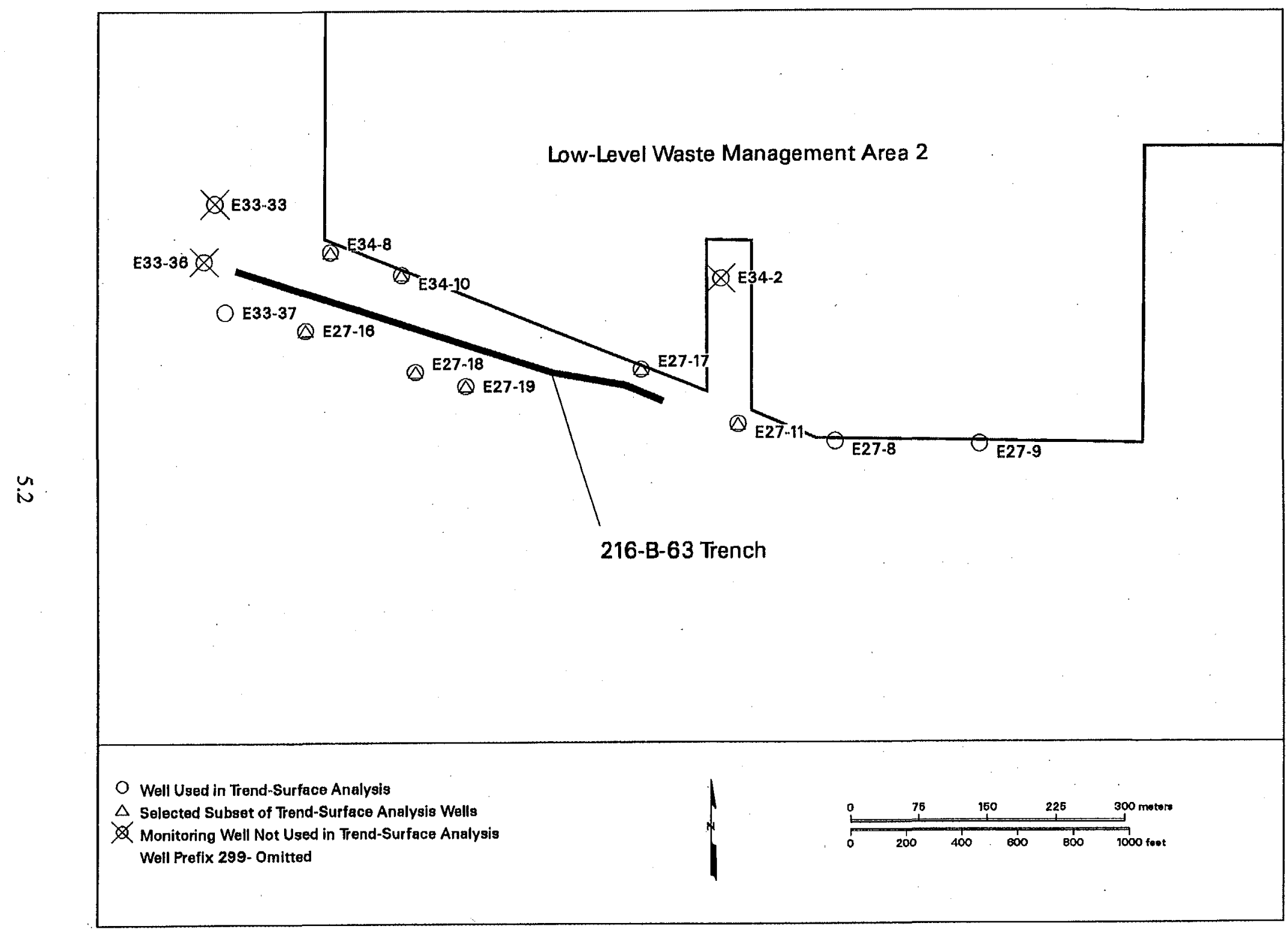

Figure 5.1. Location Map of Wells Monitoring the 216-B-63 Trench 


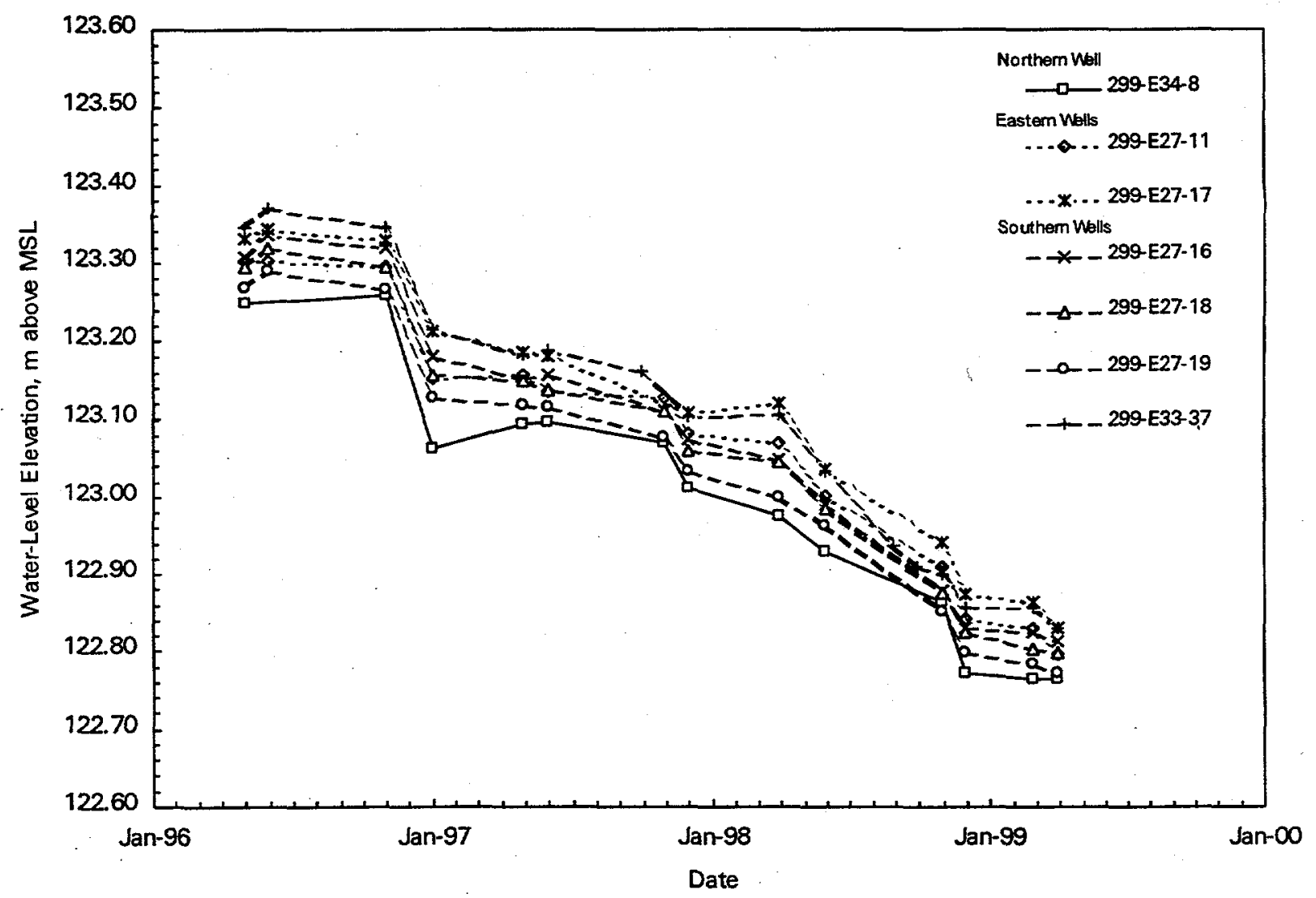

Figure 5.2. Comparison of Well Water-Level Elevation Response for Selected Wells Monitoring the 216-B-63 Trench

Water-level elevation and calculated total head values were used with the WATER-VEL program to calculate the groundwater-flow direction and hydraulic gradient. The program utilizes a linear, twodimensional trend surface (least squares) to randomly located hydrologic head or water-level elevation input data. This technique is accurate as long as the two-dimensional linear approximation is applicable (i.e., no significant vertical groundwater-flow gradients exist within the aquifer). This method is similar also to the linear approximation technique described by Abriola and Pinder (1982) and Kelly and Bogardi (1989). A report that demonstrates the use of the WATER-VEL program for calculation of groundwaterflow velocity and direction is presented in Gilmore et al. (1992).

Because surrounding well water-level measurements were collected, in some cases, over a period of several days, the effects of barometric pressure fluctuations may be expected to exert a discernible influence in calculating groundwater-flow direction and hydraulic gradient. Figure 5.3 shows the relationship of well water-level elevation measured at 10 different 216-B-63 Trench-monitoring wells and the barometric pressure fluctuation pattern over the field measurement period (November 5-6, 1996). As shown, the barometric pressure varied by $0.06 \mathrm{~m}$ during the actual period of well measurements, which compares with a maximum $0.10-\mathrm{m}$ water-level elevation difference between wells. Although this atmospheric pressure change is relatively small, because of the small differences in well water-level elevations, small changes in barometric pressure may exert a significant impact in the assessment of groundwater-flow 


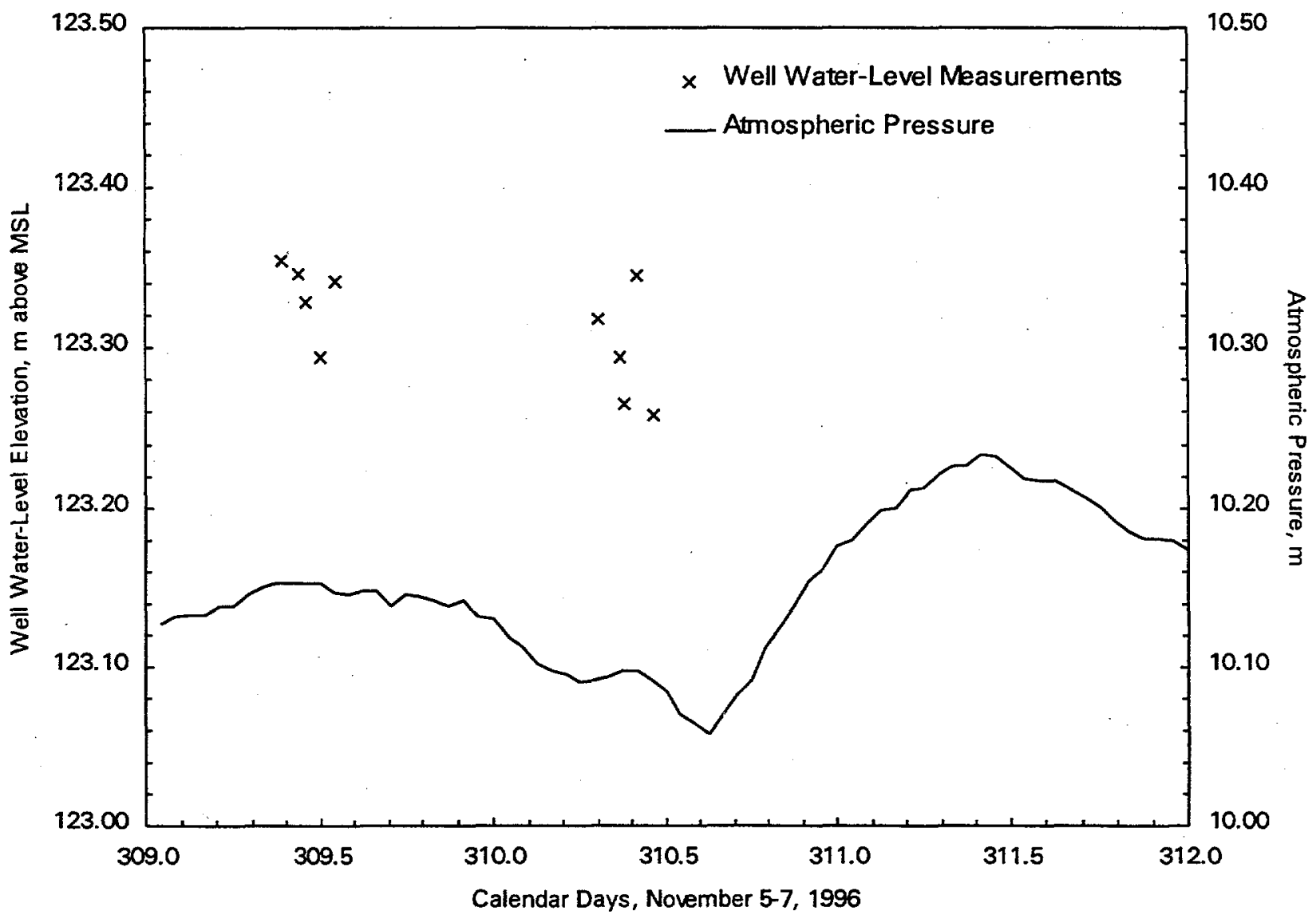

Figure 5.3. Comparison of Well Water-Level Elevation and Atmospheric Pressure for Selected Wells Monitoring the 216-B-63 Trench, November 5-6, 1996

patterns. As suggested in Figure 5.3, if the well measurements would have been delayed a day at the facility, considerably greater barometric effects would have been evident in the characterization results (i.e., a barometric pressure change of $0.18 \mathrm{~m}$ was evident between calendar days 310.5 and 311.5).

To assess this possible influence, groundwater-flow characteristics were calculated, based both on observed well water-level elevation measurements and calculated total head values (based on the recommended Hanford Site barometric reference value of $10.087 \mathrm{~m}$ ). Table 5.1 lists the results of quantitative trend-surface analysis for six measurement periods for the seven selected monitoring wells over a 2.5-year period. As shown, nearly identical results were obtained, using either water-level elevation or total head measurements. This close correspondence is attributed to the fact that most of the well measurements were collected over a relatively short period of time (i.e., within a few hours). Total head calculations, based on barometric head adjustments, would be expected to be more uniform and reflective of actual groundwater-flow patterns. The most diversity was exhibited for the November 1996 data set that was collected over a 2-day period. As indicated in Table 5.1, the results of the trend-surface analysis provide a consistent pattern of estimated flow direction (primarily southwest) and hydraulic gradient (2.1E-04 to 2.8E-04) using water-level elevation and total head measurements. The indicated 
Table 5.1. Trend-Surface Hydraulic Gradient and Groundwater-Flow Direction Determinations for Selected Wells Monitoring the 216-B-63 Trench $^{(a)}$

\begin{tabular}{|c|c|c|c|c|c|}
\hline \multirow[b]{2}{*}{ Date } & \multicolumn{2}{|c|}{$\begin{array}{l}\text { Flow Direction } \\
\left(0^{\circ}=E ; 90^{\circ}=N\right)\end{array}$} & \multicolumn{2}{|c|}{$\begin{array}{l}\text { Hydraulic Gradient } \\
\qquad(\mathrm{m} / \mathrm{m})\end{array}$} & \multirow{2}{*}{$\begin{array}{l}\text { Maximum Observed } \\
\text { Difference, m: Water- } \\
\text { Level Elevation/Total } \\
\text { Head/Barometric Head }\end{array}$} \\
\hline & $\begin{array}{l}\text { Water-Level } \\
\text { Elevation }\end{array}$ & Total Head & $\begin{array}{l}\text { Water-Level } \\
\text { Elevation }\end{array}$ & Total Head & \\
\hline November 5-6, 1996 & $247^{\circ}$ & $239^{\circ}$ & $1.8 \mathrm{E}-04$ & $5.6 \mathrm{E}-04$ & $0.088 / 0.151 / 0.063$ \\
\hline May 5-6, 1997 & $231^{\circ}$ & $233^{\circ}$ & $1.8 \mathrm{E}-04$ & $2.3 \mathrm{E}-04$ & $0.105 / 0.105 / 0.009$ \\
\hline December 4, 1997 & $224^{\circ}$ & $228^{\circ}$ & $1.8 \mathrm{E}-04$ & $2.1 \mathrm{E}-04$ & $0.098 / 0.097 / 0.003$ \\
\hline June 8, 1998 & $228^{\circ}$ & $229^{\circ}$ & $2.1 \mathrm{E}-04$ & $2.1 \mathrm{E}-04$ & $0.121 / 0.119 / 0.003$ \\
\hline December 3, 1998 & $230^{\circ}$ & $228^{\circ}$ & $2.1 \mathrm{E}-04$ & $2.0 \mathrm{E}-04$ & $0.108 / 0.108 / 0.003$ \\
\hline March 8, 1999 & $237^{\circ}$ & $235^{\circ}$ & $2.9 \mathrm{E}-04$ & $2.6 \mathrm{E}-04$ & $0.105 / 0.104 / 0.004$ \\
\hline $\begin{array}{l}\text { Average Values } \\
\text { (Standard Deviation) }\end{array}$ & $\begin{array}{c}233 \\
( \pm 8.1)\end{array}$ & $\begin{array}{c}232 \\
( \pm 4.5)\end{array}$ & $\begin{array}{c}2.1 \mathrm{E}-04 \\
( \pm 4.3 \mathrm{E}-05)\end{array}$ & $\begin{array}{c}2.8 \mathrm{E}-04 \\
( \pm 1.4 \mathrm{E}-04)\end{array}$ & $0.104 / 0.114 / 0.014$ \\
\hline
\end{tabular}

southwesterly groundwater-flow direction contrasts slightly with the reported westerly groundwaterflow direction reported in Hartman (1999); however, the consistency in the determinations with time in Table 5.1 adds credibility to the indicated groundwater-flow pattern characteristics.

For comparison purposes, Table 5.2 lists the results of quantitative analysis for the same six measurement periods using all the surrounding (ten) monitoring wells. (Note: Wells 299-E33-33 and -E33-36 were not included with the other indicated wells in the analysis because of significantly lower water-level

Table 5.2. Trend-Surface Hydraulic Gradient and Groundwater-Flow Direction Determinations for Wells Monitoring the 216-B-63 Trench $^{(a)}$

\begin{tabular}{|c|c|c|c|c|c|}
\hline \multirow[b]{2}{*}{ Date } & \multicolumn{2}{|c|}{$\begin{array}{l}\text { Flow Direction, } \\
\left(0^{\circ}=\mathrm{E} ; 90^{\circ}=\mathrm{N}\right)\end{array}$} & \multicolumn{2}{|c|}{$\begin{array}{l}\text { Hydraulic Gradient } \\
\qquad(\mathrm{m} / \mathrm{m})\end{array}$} & \multirow{2}{*}{$\begin{array}{l}\text { Maximum Observed } \\
\text { Difference, m: Water- } \\
\text { Level Elevation/Total } \\
\text { Head/Barometric Head }\end{array}$} \\
\hline & $\begin{array}{l}\text { Water-Level } \\
\text { Elevation }\end{array}$ & Total Head & $\begin{array}{l}\text { Water-Level } \\
\text { Elevation }\end{array}$ & Total Head & \\
\hline November 5-6, 1996 & $236^{\circ}$ & $238^{\circ}$ & $1.1 \mathrm{E}-04$ & 3.7E-04 & $0.097 / 0.160 / 0.063$ \\
\hline May $1,5-7,1997$ & $207^{\circ}$ & $230^{\circ}$ & $8.3 \mathrm{E}-05$ & $2.5 \mathrm{E}-04$ & $0.109 / 0.185 / 0.097$ \\
\hline December 4,1997 & $188^{\circ}$ & $205^{\circ}$ & $7.8 \mathrm{E}-05$ & $9.3 \mathrm{E}-05$ & $0.116 / 0.114 / 0.004$ \\
\hline June 8, 1998 & $194^{\circ}$ & $187^{\circ}$ & $8.0 \mathrm{E}-05$ & $7.9 \mathrm{E}-05$ & $0.121 / 0.119 / 0.003$ \\
\hline December 3-4, 1998 & $213^{\circ}$ & $226^{\circ}$ & $1.1 \mathrm{E}-04$ & $2.0 \mathrm{E}-04$ & $0.115 / 0.115 / 0.065$ \\
\hline March 8, 1999 & $229^{\circ}$ & $223^{\circ}$ & $1.6 \mathrm{E}-04$ & $1.3 \mathrm{E}-04$ & $0.118 / 0.119 / 0.005$ \\
\hline $\begin{array}{l}\text { Average Values } \\
\text { (Standard Deviation) }\end{array}$ & $\begin{array}{c}211 \\
( \pm 18.9)\end{array}$ & $\begin{array}{c}218 \\
( \pm 18.8)\end{array}$ & $\begin{array}{c}1.0 \mathrm{E}-04 \\
( \pm 3.1 \mathrm{E}-05)\end{array}$ & $\begin{array}{c}1.9 \mathrm{E}-04 \\
( \pm 1.1 \mathrm{E}-04)\end{array}$ & $0.113 / 0.135 / 0.040$ \\
\hline $\begin{array}{l}\text { Total monitoring } \\
\text {-E34-8, -E34-10 }\end{array}$ & & & & & -37 \\
\hline
\end{tabular}


elevations and different dynamic well responses.) As indicated, greater variability in groundwater-flow direction and hydraulic gradient are exhibited when screening criteria are not employed. In addition, several of the data sets for the expanded 216-B-63 Trench well network were obtained over a longer measurement period (e.g., May 1997). Water-level elevation measurements obtained over a longer period of time would be expected to exhibit greater variability because of the varying effects of barometric pressure fluctuation. These collective findings suggest that the quantitative analysis of calculated total head (rather than well water-level elevation) for monitoring wells selected on the basis of the previously recommended screening criteria may reduce uncertainty in groundwater-flow characterization in lowgradient areas. 


\subsection{Conclusions}

For detailed hydrologic investigations, water-level elevation information obtained from wells should be converted to total head measurements for quantitative analysis of groundwater-flow characteristics and hydraulic properties. Open wells, however, may exhibit a delayed response to variations in atmospheric pressure and provide erroneous indications of total head conditions within the surrounding aquifer. Barometric fluctuations represent an areal, blanket stress applied at the land surface. The manner in which a well/aquifer system responds to changes in atmospheric pressure is related directly to the existing aquifer system and wellbore-storage/well-skin conditions. Closed-well installations (i.e., systems closed below the water table) provide a means of eliminating barometric pressure-induced wellbore-storage effects and provide direct measurements for total head within the surrounding aquifer. Absolute pressure probe measurements can be utilized directly for calculating total head within the aquifer. For open-well waterlevel elevation measurements obtained from surface-based depth-to-water measurements or inferred from downhole differential pressure transducer measurements, the incremental change in barometric pressure from a site reference value should be added to the water-level measurement to obtain total hydraulic head. The reported Hanford Site, long-term, average atmospheric pressure of $10.087 \mathrm{~m}$ is recommended as the reference pressure for Hanford Site hydrologic investigations.

For determining groundwater-flow pattern characteristics in low-hydraulic gradient areas, efforts should be made to ensure that wells used in the flow analysis are highly communicative with the surrounding aquifer and exhibit similar dynamic responses to barometric fluctuations (temporal) and/or longer term hydrologic stresses (e.g., local recharge, pumping). Total head values calculated from wellbased measurements should be obtained closely in time, with atmospheric pressure noted at the time of measurement and corrected for changes from the site reference value. Trend-surface analysis of the areal total head values provides an expedited means for analyzing groups or clusters of closely spaced wells and assessing individual importance in determining groundwater-flow pattern characteristics.

For aquifer tests adversely affected by barometric fluctuations, these effects should be removed from the well water-level data prior to test analysis. Several techniques have been shown to be effective in removing the effects of barometric fluctuations:

- for unconfined aquifers

- multiple-regression deconvolution techniques

- vadose zone model (Weeks 1979)

- for confined aquifers

- multiple-regression deconvolution techniques

- Clark (1967) method.

Diagnostic barometric response analysis can be used effectively for distinguishing between confined and unconfined aquifer system behavior and identifying the presence of wellbore-storage/well-skin effects. Both diagnostic and removal methods require the collection of extended periods of corresponding baseline barometric and well water-level measurements. For Hanford Site conditions, it is recommended 
that a minimum of 5 days of baseline data be collected at a measurement frequency of every 10 to $30 \mathrm{~min}$. For unconfined aquifers, the measurement frequency is a function of water-table depth and vadose zone characteristics (i.e., for shallow depths and higher vadose zone pneumatic diffusivity values, more frequent measurements are required). For water-table depths $>50 \mathrm{~m}$ and for pneumatic diffusivity values $<0.10 \mathrm{~m}^{2} / \mathrm{s}$, it is expected that a measurement frequency of every $30 \mathrm{~min}$ can be effectively employed.

For areas and/or situations where barometric effects may significantly impact the determination of groundwater-flow patterns or aquifer test characterization, closed-well systems provide a means of eliminating complicating factors affecting open-well measurements. Closed-well installations that provide in-well isolation below the water table appear to provide the best systems for effectively removing timedelaying effects of wellbore-storage/well skin from well measurements, as well as eliminating the direct transmission of atmospheric pressure changes through the well to the water table. For unconfined aquifers, absolute pressure probe measurements, obtained in conjunction with closed-well systems, monitor the time-lagged total head response (within the aquifer) to atmospheric pressure changes occurring at land surface. For aquifer test analysis applications, barometric pressure removal methods (e.g., multipleregression deconvolution, vadose zone model) appear most effective when used in conjunction with well data collected with closed-well systems. 


\subsection{References}

Abriola LM and GF Pinder. 1982. "Calculation of velocity in three space dimensions from hydraulic head measurements." Ground Water 20(2):205-213.

Bredehoeft JD. 1967. "Response of well-aquifer systems to earth tides." Journal of Geophysical Research 72(12):3075-3087.

Butler JJ, Jr. 1998. The design, performance, and analysis of slug tests. Lewis Publishers, CRC Press, Boca Raton, Florida.

Chien YM, RW Bryce, SR Strait, and RA Yeatman. 1986. "Elimination of frequency noise from groundwater measurements." In High-level nuclear waste disposal, ed. HC Burkholder, pp. 389-400, Battelle Press, Richland, Washington.

Clark WE. 1967. "Computing the barometric efficiency of a well." American Society of Civil Engineers, Journal of the Hydraulic Division, Proceedings 93(HY4):93-98.

Cooper HH, JD Bredehoeft, and IS Papadopulos. 1967. "Response of a finite-diameter well to an instantaneous charge of water." Water Resources Research 3(1):263-269.

Davis DR and TC Rasmussen. 1993. "A comparison of linear regression with Clark's method for estimating barometric efficiency of confined aquifers." Water Resources Research 29(6):1849-1854.

DeWiest RJM. 1969. Flow through porous media. Academic Press, New York.

Domenico PA. 1972. Concepts and models in groundwater hydrology. McGraw-Hill Book Company, New York.

Earlougher RC, Jr. 1977. Advances in well test analysis. Society of Petroleum Engineers, AIME, Monograph Vol. 5, Henry L. Doherty Series, Dallas, Texas.

Erskine AD. 1991. "The effect of tidal fluctuation on a coastal aquifer in the UK." Ground Water 29(4):556-562.

Ferris JG. 1963. Cyclic fluctuations of water level as a basis for determining aquifer transmissibility. Water-Supply Paper 1536-I, U.S. Geology Survey, pp. 305-318.

Freeze RA and PA Witherspoon. 1966. "Theoretical analysis of regional groundwater flow: 1. Analytical and numerical solutions to the mathematical model." Water Resources Research 2(2):641-656. 
Freeze RA and PA Witherspoon. 1967. "Theoretical analysis of regional groundwater flow: 2. Effect of water-table configuration and subsurface permeability variation. Water Resources Research $3(2): 623-634$.

Furbish DJ. 1991. "The response of water level in a well to a time series of atmospheric loading under confined conditions." Water Resources Research 27(4):557-568.

Garber MS and FC Koopman. 1968. Methods of measuring water levels in deep wells. Techniques of Water Resources Investigations, Book 8 - Instrumentation, U.S. Geological Survey, pp. 1-23.

Gilmore TJ. 1989. The installation of the Westbay multiport ground-water sampling system in well 699-43-42K near the 216-B-3 pond. PNL-6973, Pacific Northwest Laboratory, Richland, Washington.

Gilmore TJ, SH Hall, KB Olsen, and FA Spane, Jr. 1991. Evaluation of a multiport groundwater monitoring system. PNL-7625, Pacific Northwest Laboratory, Richland, Washington.

Gilmore TJ, DR Newcomer, SK Wurstner, and FA Spane, Jr. 1992. Calculation of groundwater discharge to the Columbia River in the 100-N area. PNL-8057, Pacific Northwest Laboratory, Richland, Washington.

Hartman MJ (ed.). 1999. Hanford Site groundwater monitoring for fiscal year 1998. PNNL-12086, Pacific Northwest National Laboratory, Richland, Washington.

Heath RC. 1983. Basic ground-water hydrology. Water-Supply Paper 2220, U.S. Geological Survey.

Hoitink DJ, KW Burk, and JV Ramsdell. 1999. Climatological data summary 1998 with historical data. PNNL-12087, Pacific Northwest National Laboratory, Richland, Washington.

Hsieh PA, JD Bredehoeft, and SA Rojstaczer. 1988. "Response of well aquifer systems to earth tides: Problem revisited. Water Resources Research 24(3):468-472.

Hubbert MK. 1940. "The theory of ground-water motion." The Journal of Geology 48(8):785-944.

Hvorslev MJ. 1951. Time lag and soil permeability in groundwater observations. Bulletin 36, U.S. Army Engineers Waterways Experiment Station, Vicksburg, Mississippi.

In-Situ, Inc. 1991. WATER-VEL ${ }^{T M}$ groundwater velocity. ISI-GWV-2.21-1, Laramie, Wyoming. Jacob CE. 1940. "On the flow of water in an elastic artesian aquifer." American Geophysical Union, Transactions 14:446-460.

Jacob CE. 1950. "Flow of ground water." Chapter 5 in Engineering Hydraulics, ed. H Rouse, pp. 321-386. John Wiley \& Sons, Inc., New York. 
Kelly WE and I Bogardi. 1989. "Flow directions with a spreadsheet." Ground Water - Computer Notes 27(2):245-247.

Liu WZ and JJ Butler, Jr. 1995. The KGS model for slug tests in partially penetrating wells (Version 3.0). Computer Series Report 95-1, Kansas Geological Survey, Lawrence, Kansas.

Lusczynski NJ. 1961. "Head and flow of ground water of variable density." Journal of Geophysical Research 66(12):4247-4256.

Nelson RW. 1988. Considerations of a nonhomogeneous fluid in the deep groundwater flow system at Hanford. PNL-6725, Pacific Northwest Laboratory, Richland Washington.

Novakowski KS. 1990. "Analysis of aquifer tests conducted in fractured rock: A review of the physical background and the design of a computer program for generating type curves." Ground Water 28(1):99-107.

Oberlander PL. 1989. "Fluid density and gravitational variations in deep boreholes and their effect on fluid potential." Ground Water 27(3):341-350.

Quilty EG and EA Roeloffs. 1991. "Removal of barometric pressure response from water level data." Journal of Geophysical Research 96(B6):10,209-10,218.

Rasmussen TC and LA Crawford. 1997. "Identifying and removing barometric pressure effects in confined and unconfined aquifers." Ground Water 35(3):502-511.

Rojstaczer S. 1988. "Determination of fluid flow properties from the response of water levels in wells to atmospheric loading." Water Resources Research 24(11):1927-1938.

Spane FA, Jr. 1987. Fresh-water potentiometric map and inferred lateral groundwater flow direction for the Mabton interbed, Hanford Site, Washington State -- January 1986. SD-BWI-TI-335, Rockwell Hanford Operations, Richland, Washington.

Spane FA, Jr. 1992. Applicability of slug interference tests under Hanford Site test conditions: Analytical assessment and field test evaluation. PNL-8070, Pacific Northwest Laboratory, Richland, Washington.

Spane FA, Jr. 1993. Selected hydraulic test analysis techniques for constant-rate discharge tests. PNL-8539, Pacific Northwest Laboratory, Richland, Washington.

Spane FA, Jr. and RB Mercer. 1985. HEADCO: A program for converting observed water levels and pressure measurements to formation pressure and standard hydraulic head. RHO-BW-ST-71 P, Rockwell Hanford Operations, Richland, Washington. 
Spane FA, Jr. and PD Thorne. 1986. Comparison of calculated and observed hydrostatic pressure measurements at borehole DC-8. RHO-BW-ST-74 P, Rockwell Hanford Operations, Richland, Washington.

Spane FA, Jr. and PD Thorne. 1995. Comparison of constant-rate pumping test and slug interference test results at the Hanford Site B pond multilevel test facility. PNL-10835, Pacific Northwest Laboratory, Richland, Washington

Spane FA, Jr., PD Thorne, and LC Swanson. 1996. "Applicability of slug interference tests for hydraulic characterization of unconfined aquifers: (2) Field test examples." Ground Water 34(5):925-933.

Toth J. . 1963. "A theoretical analysis of groundwater flow in small drainage basin." Journal of Geophysical Research 68(16):4795-4812.

Toth J. 1978. "Gravity-induced cross-formational flow of formation fluids, Red Earth Region, Alberta, Canada: Analysis, patterns, and evolution." Water Resources Research 14(5):805-843.

Weeks EP. 1979. "Barometric fluctuations in wells tapping deep unconfined aquifers." Water Resources Research 15(5):1167-1176.

Winograd I. 1970. "Noninstrumental factors affecting measurement of static water levels in deeply buried aquifers and aquitards, Nevada Test Site." Ground Water 8(2):1-33.

Washington Administrative Code (WAC). 1990. "Minimum standards for construction and maintenance of wells." WAC 173-160, Olympia, Washington. 


\section{Distribution}

No. of

Copies

\section{Offsite}

R. Buck, Jr.

Wanapum Indian Band

P.O. Box 878

Ephrata, WA 98823

J. Butler

Geohydrology Section

Kansas Geological Survey

University of Kansas

Lawrence, KS 66047

2 Confederated Tribes of the Umatilla

Indian Reservation

Environmental Planning/Rights Protection

P.O. Box 638

Pendleton, OR 97801

ATTN: T. Gilmore

J. R. Wilkerson

\section{R. A. Danielson}

State of Washington Department of Health

2 South $45^{\text {th }}$ Avenue

Yakima, WA 98908

B. W. Drost

Geological Survey

U.S. Department of the Interior

1201 Pacific Avenue, Suite 600

Tacoma, WA 98402

W. N. Herkelrath

Geological Survey

U.S. Department of the Interior

345 Middlefield Road, MS 496

Menlo Park, CA 94025
No. of

Copies

2 Idaho National Engineering and Environmental Laboratory

Lockheed Martin Idaho Technology Co.

P.O. Box 1625

Idaho Falls, ID 83415-2107

ATTN: J. M. Hubbell

J. B. Sisson

3 Nez Perce Tribe

Environmental Restoration/Waste

Management

P.O. Box 365

Lapwai, ID 83540-0365

ATTN: P. Danielson

D. Pawaukee

S. Sobczyk

T. C. Rasmussen

Hydrology and Environmental Systems

Warnell School of Forest Resources

The University of Georgia

Athens, GA 30602-2152

2 Schlumberger HydroGeological

Technologies

6090 Greenwood Plaza Blvd.

Englewood, CO 80111

ATTN: R. Lewis

N. Clayton

E. Weeks

U.S. Geological Survey

Box 25046

Building 53, Room 2910

Denver Federal Center

Lakewood, CO 80225

J. Winterle

Southwest Research Institute/CNWRA 6220 Culebra Road, Bldg. 189A

San Antonio, TX 78238-5166

Distr.1 
No. of

Copies

2 Yakima Indian Nation

Environmental Restoration/Waste

Management

P.O. Box 151

Toppenish, WA 98948

ATTN: R. Jim

W. Rigsby

\section{Foreign}

J. Delay

ANDRA

National Radioactive Waste Management Agency

Scientific Division

Hydrogeology and Geochemistry .

Parc de la Croix Blanche

$1-7$, rue Jean Monnet

92298 Chatenay

Malabry Cedex, France

M. Hagood

Schlumberger

Parkstraat 83

2514 JG The Hague

The Netherlands

4 NAGRA

Hardstrasse 73

CH-5430

Wettingen, Switzerland

ATTN: B. Frieg

T. Kuepfer

C. Sprecher

S. Vomvoris

3 Westbay Instruments, Inc.

\#115-949 W. Third Street

North Vancouver, British Columbia

Canada V7P 3P7

ATTN: W. Black

D. Larssen

F. Patton
No. of

Copies

L. Wouters

ONDRAF/NIRAS

Madouplein 1

1210 Brussels, Belgium

Onsite

16 DOE Richland Operations Office

M. J. Furman

$\mathrm{H} 0-12$

R. D. Hildebrand (10)

$\mathrm{H} 0-12$

D. E. Olson

$\mathrm{H} 0-12$

K. M. Thompson

$\mathrm{H} 0-12$

A. C. Tortoso

$\mathrm{H} 0-12$

Public Reading Room (2)

$\mathrm{H} 2-53$

Bechtel Hanford, Inc.

B. H. Ford

H0-21

5 CH2M Hill Hanford, Inc.

J. V. Borghese

$\mathrm{H} 0-21$

R. L. Jackson

H9-03

W. J. McMahon

H9-03

V. J. Rohay

$\mathrm{H} 0-21$

L. C. Swanson

H9-02

Lockheed Martin Hanford Corporation
A. J. Knepp
H0-22

2 State of Washington Department of Ecology

D. Goswami

B5-18

S. Leja

B5-18

3 U.S. Environmental Protection Agency

D. A. Faulk

B5-01

L. E. Gadbois

B5-01

D. R. Sherwood

B5-01 
No. of

Copies

4 Waste Management Federal Services, Inc., Northwest Operations

D. R. Brewington

H1-11

M. G. Gardner

H1-11

D. E. Hollingsworth

H1-11

S. H. Worley

H1-11

4 Waste Management Federal Services of Hanford, Inc.

R. D. Haggard

G1-29

K. J. Lueck

S6-72

P. M. Olson

S6-72

R. W. Szelmeczka

S6-72

62

\section{Pacific Northwest National Laboratory}

D. B. Barnett

M. P. Bergeron

K6-81

M. A. Chamness

K9-36

C. R. Cole

K6-85

P. E. Dresel

M. J. Fayer

M. D. Freshley

G. W. Gee

T. J Gilmore

M. J. Hartman
No. of

Copies

F. N. Hodges

K6-81

V. G. Johnson

K6-96

G. V. Last

K6-81

K6-96

K6-81

K6-96

K6-96

K6-96

K6-96

K6-96

K9-33

K6-96

K6-81

K6-96

K6-96

K6-96

K6-96

K6-96

K6-96

K6-81

K9-33

K6-96

K6-96

K6-96

K9-36

K6-81

B. A. Williams

K9-36

S. K. Wurstner

K1-06 